\title{
A Multiscale Evaluation of Multisensor Quantitative Precipitation Estimates in the Russian River Basin
}

\author{
JANICE L. BythewAy AND Mimi HugheS \\ Cooperative Institute for Research in Environmental Sciences, University of Colorado Boulder, and \\ NOAA/Earth Systems Research Laboratory/Physical Sciences Division, Boulder, Colorado \\ KELly MAHONEY AND ROBERT CIFELLI \\ NOAA/Earth Systems Research Laboratory/Physical Sciences Division, Boulder, Colorado
}

(Manuscript received 6 July 2018, in final form 20 December 2018)

\begin{abstract}
The Russian River in northern California is an important hydrological resource that typically depends on a few significant precipitation events per year, often associated with atmospheric rivers (ARs), to maintain its annual water supply. Because of the highly variable nature of annual precipitation in the region, accurate quantitative precipitation estimates (QPEs) are necessary to drive hydrologic models and inform water management decisions. The basin's location and complex terrain present a unique challenge to QPEs, with sparse in situ observations and mountains that inhibit remote sensing by ground radars. Gridded multisensor QPE datasets can fill in the gaps but are susceptible to both the errors and uncertainties from the ingested datasets and uncertainties due to interpolation methods. In this study a dense network of independently operated rain gauges is used to evaluate gridded QPE from the Multi-Radar Multi-Sensor (MRMS) during 44 precipitation events occurring during the 2015/16 and 2016/17 wet seasons (October-March). The MRMS QPE products matched the gauge estimates of precipitation reasonably well in approximately half the cases but failed to capture the spatial distribution and intensity of the rainfall in the remaining cases. ERA-Interim reanalysis data suggest that the differences in performance are related to synoptic-scale patterns and AR landfall location. These synoptic-scale differences produce different rainfall distributions and influence basin-scale winds, potentially creating regions of small-scale precipitation enhancement or suppression. Data from four profiling radars indicated that a larger fraction of the precipitation in poorly captured events occurred as shallow stratiform rain unobserved by radar.
\end{abstract}

\section{Introduction}

The Russian River carves a 177-km path through Mendocino and Sonoma Counties in Northern California, providing water for hundreds of thousands of residents and acres of agriculture, and a home for several endangered or threatened species of salmon and trout. Therefore, water managers in the basin must strike a balance between flood mitigation, storage for residential and irrigation needs, and maintaining sufficient flows to sustain the river's ecosystem (Dettinger et al. 2011; Kingsmill et al. 2006). Maintaining this balance can be challenging because a significant portion of the basin annual precipitation falls during the wet season of October-March. Up to $50 \%$ of the annual precipitation coincides with the landfall of atmospheric rivers (ARs; see the appendix for a

Corresponding author: Janice L. Bytheway, janice.bytheway@ noaa.gov list of acronym expansions), long $(>2000 \mathrm{~km})$, narrow $(<1000 \mathrm{~km})$ corridors of strong poleward water vapor transport typically found in the warm sector of an extratropical cyclone (Dettinger et al. 2011; Ralph et al. 2006, 2013; Neiman et al. 2008; Lamjiri et al. 2017).

The strength and frequency of landfalling ARs can vary widely from year to year due to both seasonal variability and variability in large-scale circulation patterns (Gershunov et al. 2017; Mundhenk et al. 2016). Northern California relies on a relatively small number of these high-impact storms for a significant portion of its annual water supply, so a small increase or decrease in annual landfalling ARs can quickly result in either flooding or drought (Dettinger et al. 2011). Of the seven flooding events that occurred in the Russian River basin between 1997 and 2006, all occurred under landfalling AR conditions (Ralph et al. 2006).

The decision to store or release reservoir water depends on both antecedent and forecast precipitation and 

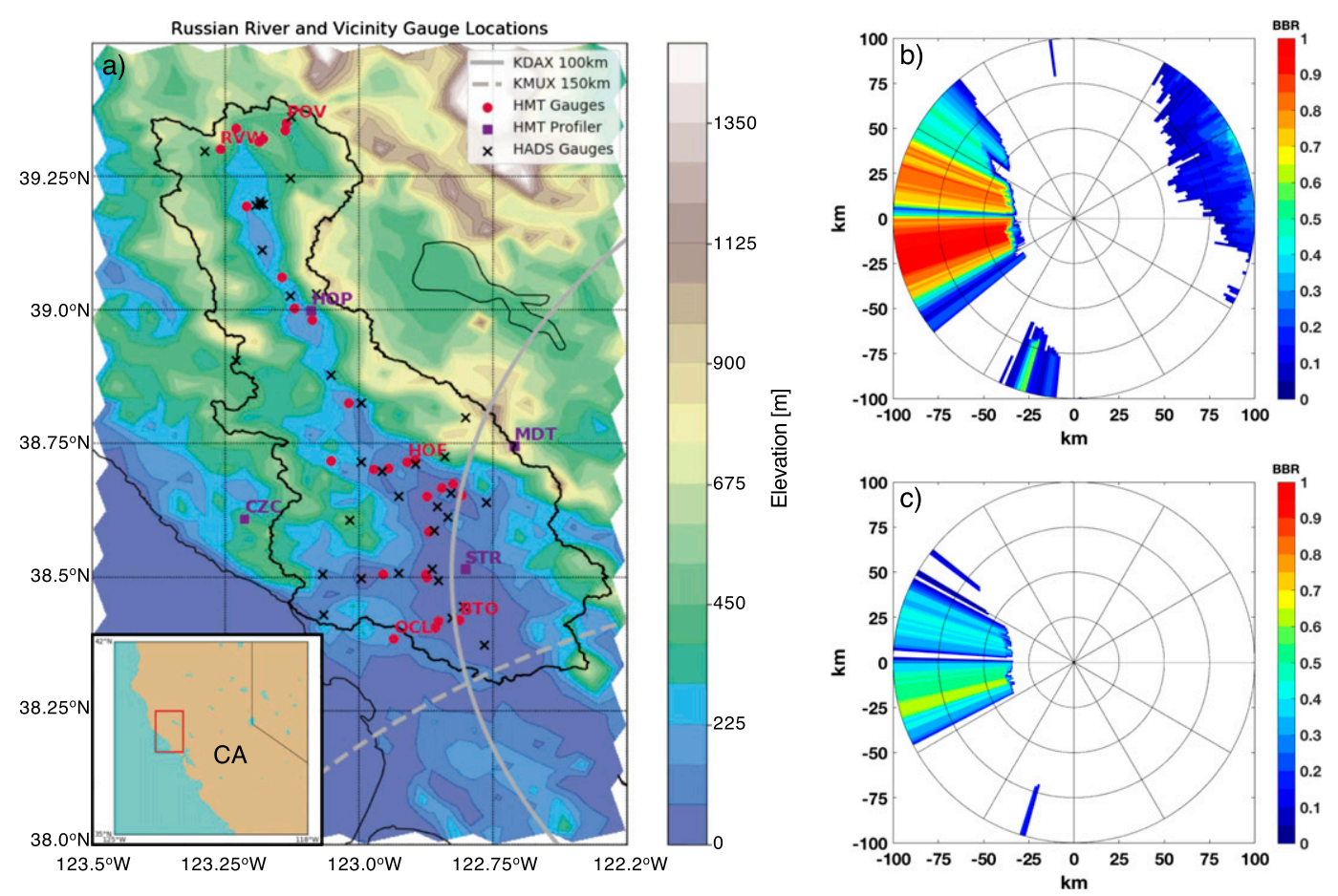

FIG. 1. (a) Location and terrain of the Russian River basin. Locations of HMT gauges used as reference in this study are shown by red circles, with relevant locations discussed in the text labeled with their three-letter identifiers. HMT gauges marked with purple squares indicate HMT gauge locations with collocated profiling radars. Locations of HADS gauges used in the MRMS QPE are indicated by black " $X$ "s. Range rings for the two nearest operational radars are indicated in gray [100 km (solid) for KDAX to the west and $150 \mathrm{~km}$ (dashed) for KMUX to the south]. BBR for KDAX (b) $0.5^{\circ}$ and (c) $0.9^{\circ}$ elevation scans. KDAX is located approximately due east of Santa Rosa [STR in (a)]. The 100-km range in (b) and (c) corresponds to the solid gray line in (a).

is typically informed by output from hydrologic models, whose accuracy depends on the model forcings, especially quantitative precipitation estimates (QPEs). QPEs represent the largest source of uncertainty in hydrologic models due to the data used, interpolation methods, and sampling issues, with a nonlinear relationship between QPE errors and errors in modeled streamflow output (Biemans et al. 2009; Gourley and Vieux 2005; Daly et al. 2017).

For this reason, accurate QPEs in the Russian River basin are crucial yet difficult to achieve (Willie et al. 2017). The Russian River lies between the Mayacamas Mountains to the east and the Coastal Range to the west (Fig. 1a). Although these ranges are less prominent $[500-1500 \mathrm{~m}$ above mean sea level (MSL)] than the Sierra Nevada farther east ( $>4 \mathrm{~km} \mathrm{MSL}$ ), the complex topography of the Russian River Valley interacts with the significant low-level moisture transport found in ARs to cause orographic precipitation enhancement (Neiman et al. 2002; Cordeira et al. 2017; Neiman et al. 2008). Even smallscale orographic influences can produce large variations in precipitation that may be embedded within larger-scale orographic effects (e.g., an individual peak within a larger range; Henn et al. 2018; Daly et al. 1994). Daly et al. (2017) indicate that orographic effects on precipitation are most important at scales of 5-10 km. Such small-scale areas of orographic enhancement or suppression can only be seen by a dense observation network.

Remote sensing of precipitation by ground-based radars is one of the highest spatial and temporal resolution sources of QPEs available, however, the complex terrain of the region interferes with these observations. The Russian River basin is over $100 \mathrm{~km}$ from the nearest National Weather Service (NWS) operational weather radar (WSR-88D) at Sacramento (KDAX), and the beam of the lowest-angle scans from KDAX is mostly blocked by the terrain (Figs. 1b,c; Maddox et al. 2002; Matrosov et al. 2014). Since the rainfall associated with landfalling ARs often occurs within shallow stratiform systems (White et al. 2003), radar beams that are high enough to see over the topography are often also high enough to pass over the top of shallow stratiform rainfall. In less-shallow precipitating systems, higher parts of the cloud will be sampled, resulting in biases in the estimated surface rainfall (Matrosov et al. 2014; Fabry et al. 1994; Villarini and Krajewski 2010). 
To capture the small-scale impacts of topography on precipitation, a dense network of observing sites is necessary (Henn et al. 2018). The Physical Sciences Division at the National Oceanic and Atmospheric Administration's Earth Systems Research Laboratory (NOAA/ ESRL/PSD) operates gauges in the Russian River Valley as part of the Hydrometeorology Testbed-West (HMT) legacy network. PSD also maintains an archive of data from gauges operated by the Russian River Habitat Blueprint Network (RRHBN) and Western Weather, providing 33 gauge-based rainfall estimates in the Russian River basin (collectively referred to as the HMT network hereafter). The largest distance between HMT gauges in the Russian River basin is $18.5 \mathrm{~km}$, with an average separation of $4.5 \mathrm{~km}$. The gauge site elevations range from $29 \mathrm{~m}$ MSL at Sebastopol to $972 \mathrm{~m}$ MSL at Middletown (BTO and MDT in Fig. 1a, respectively). While the HMT gauges comprise a relatively dense network, they do not cover the basin in its entirety; like most gauge-based networks, they somewhat undersample the highest elevations. Nevertheless, they make up a relatively dense, independent network that can provide insight on the effects of small-scale topographic features on precipitation.

QPEs in these areas rely on high-resolution gridded products that interpolate between gauge observations and/ or incorporate multiple sources of QPE into a single precipitation estimate. The Multi-Radar Multi-Sensor (MRMS; Zhang et al. 2011, 2016) QPE is one such product, providing high-resolution (hourly, $\sim 1 \mathrm{~km}$ ) gridded QPEs combining data from gauges, radars, and statistical relationships between elevation and precipitation. Here, we evaluate a subset of the MRMS products against the HMT gauges (which are independent of the gauges used to produce the MRMS) at the HMT gauge locations to examine how well the gridded products capture the smallscale variations in precipitation due to topography. MRMS QPEs are evaluated for 44 events that occurred during the 2015/16 and 2016/17 wet seasons (OctoberMarch) in the Russian River basin. These seasons are of interest because of the expected, but absent, heavy precipitation during the strong 2015/16 El Niño, and the unexpected record precipitation during the weak 2016/ 17 La Niña. Patterns for the MRMS behavior due to synoptic-scale, mesoscale, and storm-scale characteristics will be discussed.

\section{Data}

\section{a. MRMS QPE}

The MRMS QPE products are produced operationally at the National Centers for Environmental Prediction (NCEP) and distributed to NWS forecast offices and several external agencies. MRMS combines estimates of precipitation from various observational networks to produce hourly rainfall estimates on a $0.01^{\circ}$ grid (Zhang et al. 2011, 2014, 2016). MRMS products may incorporate information from both U.S. and Canadian operational radar networks, gauge data, climatology, and environmental output from numerical weather prediction models. MRMS produces four QPE products incorporating different inputs: radar-only, gauge-only, gauge-adjusted radar, and Mountain Mapper. In this paper we will focus on the evaluation of the latter two products, that is, the gauge-adjusted radar and Mountain Mapper. Given the generally sparse distribution of gauges and low radar coverage in the basin, the products incorporating the most available data are likely the most reliable options.

\section{1) MRMS GAUGE-ADJUSTED RADAR}

The MRMS gauge-corrected radar product (MRMSGC) ingests radar reflectivity data from the U.S. WSR88D network as well as C-band radars from Environment Canada (now Environment and Climate Change Canada), resulting in a spatial domain covering the continental United States (CONUS) and southern Canada. Radar coverage is often unreliable in the western United States due to beam blockage by the terrain (Maddox et al. 2002), and radar-based QPE products have several sources of uncertainty, including calibration errors, nonprecipitating echoes (i.e., clutter), $Z-R$ relationship uncertainty, vertical variability of the precipitation, precipitation drift due to wind, and sampling errors (Fabry et al. 1994; Villarini and Krajewski 2010; Zhang et al. 2014). Several automated steps are taken to mitigate these uncertainties in the MRMS products, including the use of dual-polarization radar variables to identify nonhydrometeor echoes, a Radar Quality Index (RQI) that identifies quality issues associated with beam blockage and beam spreading, and the use of five different $Z-R$ relationships for use with different precipitation types (Zhang et al. 2016).

Radar-based estimates of precipitation are adjusted using a network of approximately 7000 gauges from the Hydrometeorological Automated Data System (HADS) network (Kim et al. 2009). Like radar, gauge estimates are subject to many sources of uncertainty including calibration issues, undercatch due to wind, frozen gauges, clogged gauges, power failures, and evaporative losses (Ciach 2003; Daly et al. 2017; Habib et al. 2001; Kim et al. 2009; Qi et al. 2016). The MRMS algorithm performs an automated HADS quality control (QC) process prior to adjusting the radar-based rainfall estimates. This process compares the gauges to collocated radar pixels that have an RQI greater than 0.1 (on a $0-1$ scale) and identifies gauges with false zero values, falsely identified precipitation, and rain rates that are too high or too low 
compared to the radar. For gauges in areas with RQI less than 0.1 , several checks on the gauge data are still performed, including the use of surface wet-bulb temperature output from the Rapid Update Cycle (RUC) model to identify areas of potentially frozen precipitation and remove data from gauges that likely represent snow and ice, and flagging gauges with hourly rainfall exceeding 2 in. $(50.8 \mathrm{~mm})$ as being possible extreme values (Zhang et al. 2016).

Hourly analyses of temperature and wet-bulb temperature from the RUC are also used to determine freezing level (i.e., height of the melting layer) in addition to the potential for frozen precipitation at the surface. Humidity and wind fields are also used to identify areas of potential precipitation enhancement.

After identifying regions of acceptable radar quality and applying the automated gauge QC, the gauge-adjustment of the radar precipitation estimates follows three steps. First, hourly differences between the radar and gauge are calculated at gauge locations. These differences are then interpolated onto the 1-km MRMS grid via inverse distance weighting. Finally, the interpolated difference field is subtracted from the radar QPE field (Zhang et al. 2016). The resulting MRMS-GC product is available as estimates of hourly accumulation that are updated every $2 \mathrm{~min}$.

\section{2) MRMS MOUNTAIN MAPPER}

The MRMS Mountain Mapper product (MRMS-MM) interpolates the HADS gauge data to nongauge locations and adjusts for orography using the Parameter-Elevation Regressions on Independent Slopes Model (PRISM; Daly et al. 1994, 2017), which uses a digital elevation model (DEM) to calculate linear relationships between precipitation and elevation at monthly and annual scales. Zhang et al. (2014, 2016) found Mountain Mapper QPEs to be consistently better than radar-based precipitation estimates in regions where radar coverage is unreliable, such as the western United States.

The application of the precipitation-elevation adjustment to the gauge-only analysis to produce MRMS$\mathrm{MM}$ is similar to that used to apply gauge adjustment to the radar-only QPE to produce the MRMS-GC. The ratio between quality-controlled hourly gauge observations and collocated grid points in the PRISM climatology is calculated and then interpolated using inverse distance weighting onto the 1-km MRMS grid.

\section{b. HMT gauges}

The Physical Sciences Division at NOAA/ESRL operates a number of rain gauges in the western United States, with additional gauges available via collaborations with Western Weather and RRHBN. These networks combined provide 33 gauges in the Russian River basin and vicinity (Fig. 1a). Because a majority of the gauges are located in the valley along the river, additional gauges just outside the basin [Cazadero (CZC), Occidental (OCL), and Middletown (MDT)] are also included to provide precipitation estimates at higher elevations. The HMT gauges are not part of the HADS network and are not incorporated into the MRMS products, making this network useful for comparison to the MRMS QPEs.

Although the HMT gauge network is generally well maintained by PSD staff, the gauges are not immune from the uncertainties typical to gauge networks (Ciach 2003; Habib et al. 2001; Qi et al. 2016; Kim et al. 2009; Daly et al. 2017). Therefore, manual quality control partially following the methodology of Blenkinsop et al. (2017) was performed on the gauges and any questionable data were removed. First, gauges were removed from consideration if more than $25 \%$ of hourly observations during their period of record was missing (two gauges removed). Then, gauges were flagged when their hourly or daily accumulated precipitation exceeded record maxima (as reported by the NWS) by more than $20 \%$. Additionally, 6-hourly accumulation totals were compared to both neighboring gauges and 6-hourly NCEP Stage IV QPE (Lin and Mitchell 2005; Nelson et al. 2016). Gauges that either indicated zero accumulation when both Stage IV and its neighbors recorded rainfall or had suspicious repeated values when both Stage IV and its neighbors indicated no rain were flagged. A gauge flagged as questionable for any period of a precipitating event was removed from consideration for the entirety of that event, thus reducing the chance of including data that may have been part of the QC issue but was not obviously flagged. Overall, 22 events had at least one gauge removed from consideration, with 6 gauges omitted for more than one event.

\section{c. S-band vertical profiling radars}

The HMT rain gauges at CZC, MDT, Hopland (HOP), and Santa Rosa (STR) are collocated with S-band $(\lambda=$ $10 \mathrm{~cm}$ ) vertical profiling radars (Ecklund et al. 1999; White et al. 2000) that provide a continuous view of the vertical structure and evolution of precipitating systems that pass over them. The vertical profiles of reflectivity and velocity can be used to determine the presence and location of the bright band, a layer of enhanced reflectivity caused by melting hydrometeors (White et al. 2002). Data from these radars will be used in section $5 \mathrm{c}$ to discuss vertical rainfall characteristics and how they relate to MRMS QPE performance.

\section{d. Reanalysis data}

Reanalysis data were used to examine the synoptic and mesoscale characteristics of the events impacting 
the Russian River basin as they pertain to MRMS performance. For synoptic conditions, 6-hourly analysis fields of integrated vapor transport (IVT), total precipitable water (TPW), 500-hPa geopotential height, mean sea level pressure (MSLP), 10-m wind, and 250-hPa wind from the ERA-Interim reanalysis (Dee et al. 2011) were examined on a $0.5^{\circ}$ grid. To further examine how near-surface winds interacted with the complex small-scale terrain features in and around the basin, $10-\mathrm{m}$ winds at $2.5-\mathrm{km}$ resolution were also obtained from the NCEP Real-Time Mesoscale Analysis (RTMA; De Pondeca et al. 2011).

\section{Methods}

Over the course of the 2015/16 and 2016/17 wet seasons (October-March), precipitating events impacting the Russian River basin were identified using the MRMS-GC product in a manner similar to that described by Lamjiri et al. (2017). Events are characterized by eight or more continuous hours where at least one grid point within the basin received at least $0.254 \mathrm{~mm}$ of precipitation (the minimum detectable by gauge). A new event begins following a period of at least $6 \mathrm{~h}$ with no precipitation within the basin. Rain-free periods of less than $6 \mathrm{~h}$ were included within an encompassing event. Once identified, only events where total accumulation exceeds $5 \mathrm{~mm}$ for at least one of the HMT gauge sites are considered. In this way, we attempt to evaluate only the most impactful events, while avoiding events with very short duration, small spatial coverage, or scattered rain, all of which would have significant uncertainty due to the sampling limitations of both the MRMS and HMT gauges. Events with large quantities of missing data from the MRMS-GC, MRMS-MM, or HMT gauges were also removed from consideration, resulting in 44 unique events ( 25 in the first season and 19 in the second) for assessment.

Following QC of the HMT data and identification of events, the storm total rainfall for each of the MRMS products (MM and GC) was compared to that from the HMT gauges. Because of the large variability in storm duration and intensity (and therefore total accumulation), all values were normalized by the maximum accumulation at any HMT gauge for each event. The event maximum accumulation occurs at the highelevation gauges at either MDT or CZC in $50 \%$ of the cases, and in the Redwood/Potter Valleys (RVW, POV, and neighboring gauges in Fig. 1a) in $20 \%$ of the cases. This normalization results in gauge values from 0 to 1 and MRMS values generally falling within the same range, with some events having values greater than 1 .

\section{Results}

Using the normalized event total rainfall to calculate the correlation coefficient $r^{2}$ and linear fit of the MRMS data to the gauge observations, a pattern quickly emerged in scatterplots comparing the MRMS QPEs to that observed at HMT gauge sites. MRMS representation of normalized event total rainfall in the Russian River basin fell into one of two general categories, examples of which are shown in Fig. 2. In Fig. 2a, both the MRMS-GC and MRMS-MM products are well correlated to the gauges, with both $r^{2}$ and the slope $m$ of the linear fit between the gridded products and the gauges greater than 0.5 . On the other hand, the comparison in Fig. 2c shows a fairly flat distribution, and when compared to the HMT gauges both the MRMS-GC and MRMS-MM products have a slope less than 0.45 , regardless of $r^{2}$. Using these numerical definitions, 42 of the 44 cases were categorized as either "well-correlated" (both $r^{2}$ and $m>0.5$ ) or "uncorrelated" $(m<0.45)$. The remaining two cases were eventually categorized by comparing the spatial distribution of precipitation during these events to the composite spatial distributions of the clearly defined events (Fig. 4). Roughly half of the cases fit into each category: 21 wellcorrelated events and 23 uncorrelated events. Figures $2 b$ and $2 \mathrm{~d}$ show the average normalized event total rainfall for the two categories, which retain characteristics similar to the example cases shown in Figs. 2a and 2c.

Figure 3 displays box-and-whisker plots of storm characteristics for the two categories of events as observed by the HMT gauges. Boxes indicate the interquartile range (IQR), with the median indicated by the horizontal line. Whiskers show the range of the data, with outliers exceeding the 25 th and 75 th percentiles by $1.5 \times$ IQR . Figure $3 \mathrm{c}$ shows all gauges individually for each event ( $\sim 1400$ data points), so the seemingly large number of outliers is a representation of the highly variable nature of the spatial distribution of precipitation in the basin. In general, well-correlated events have median duration $\sim 10 \mathrm{~h}$ longer than the uncorrelated cases. They also produce more intense rainfall: median values of both total accumulation and hourly intensities are approximately 1.6 times their uncorrelated counterparts. These characteristics are common in all three datasets [HMT gauges and both MRMS QPEs (not shown)]. Although the uncorrelated cases are typically less intense than wellcorrelated cases, they produce on average over $30 \%$ of the precipitation recorded at the HMT gauges. To investigate possible reasons for the two behavior patterns, we examine the spatial distribution of rainfall for the wellcorrelated and uncorrelated cases. The average normalized event total rainfall at each gauge station indicates distinct differences in the spatial distribution of rainfall 

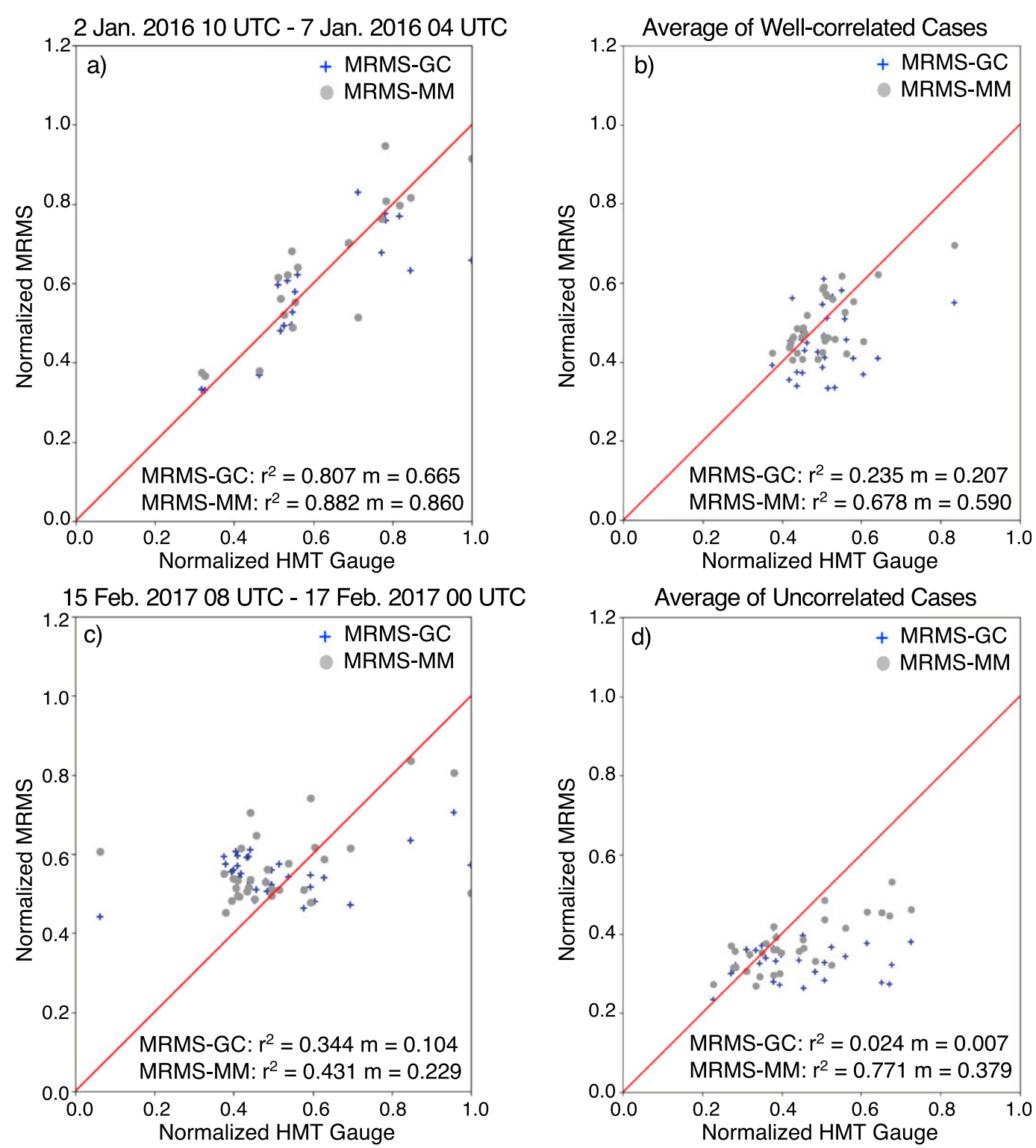

FIG. 2. Normalized event total rainfall from MRMS-GC (blue) and MRMS-MM (gray) compared to HMT gauges. (a) Example well-correlated case from January 2016, with both $r^{2}$ and $m>0.5$. (c) Example uncorrelated case from February 2017 with $m<0.45$. Average normalized event total rainfall at each gauge site for (b) well-correlated and (d) uncorrelated cases.

between the well-correlated and uncorrelated cases (Fig. 4). Well-correlated cases tend to have maximum total rainfall at the MDT gauge (average normalized total of 0.8 ), which is not unexpected since it is the highestelevation gauge site (Figs. 1a, 4a). CZC, another highelevation HMT gauge site near the coast, receives the second-highest average normalized total rainfall in wellcorrelated cases $(\sim 0.68)$. Within the valley itself, rainfall at HMT gauge sites is relatively uniform and widespread, with most gauges receiving on average $40 \%-50 \%$ of the basin maximum, with up to $60 \%$ in the higher elevations to the north. The MRMS-MM product shows a similar pattern to the gauges (Fig. 4c), with the highest values at MDT and CZC ( $\sim 0.7$ and $\sim 0.6$, respectively), and normalized rainfall of approximately $0.4-0.5$ within the rest of the valley. In the MRMS-GC product (Fig. 4b), MDT is still among the highest amounts, but nearly all of the remaining gauge sites show an average ratio of $\sim 0.45$ of the basin maximum accumulation. Overall, for well-correlated cases, both the HMT gauges and MRMS QPE products indicate fairly widespread and uniform rainfall throughout the basin with enhancement at higher elevations, with the 


\section{HMT Gauge Observations}
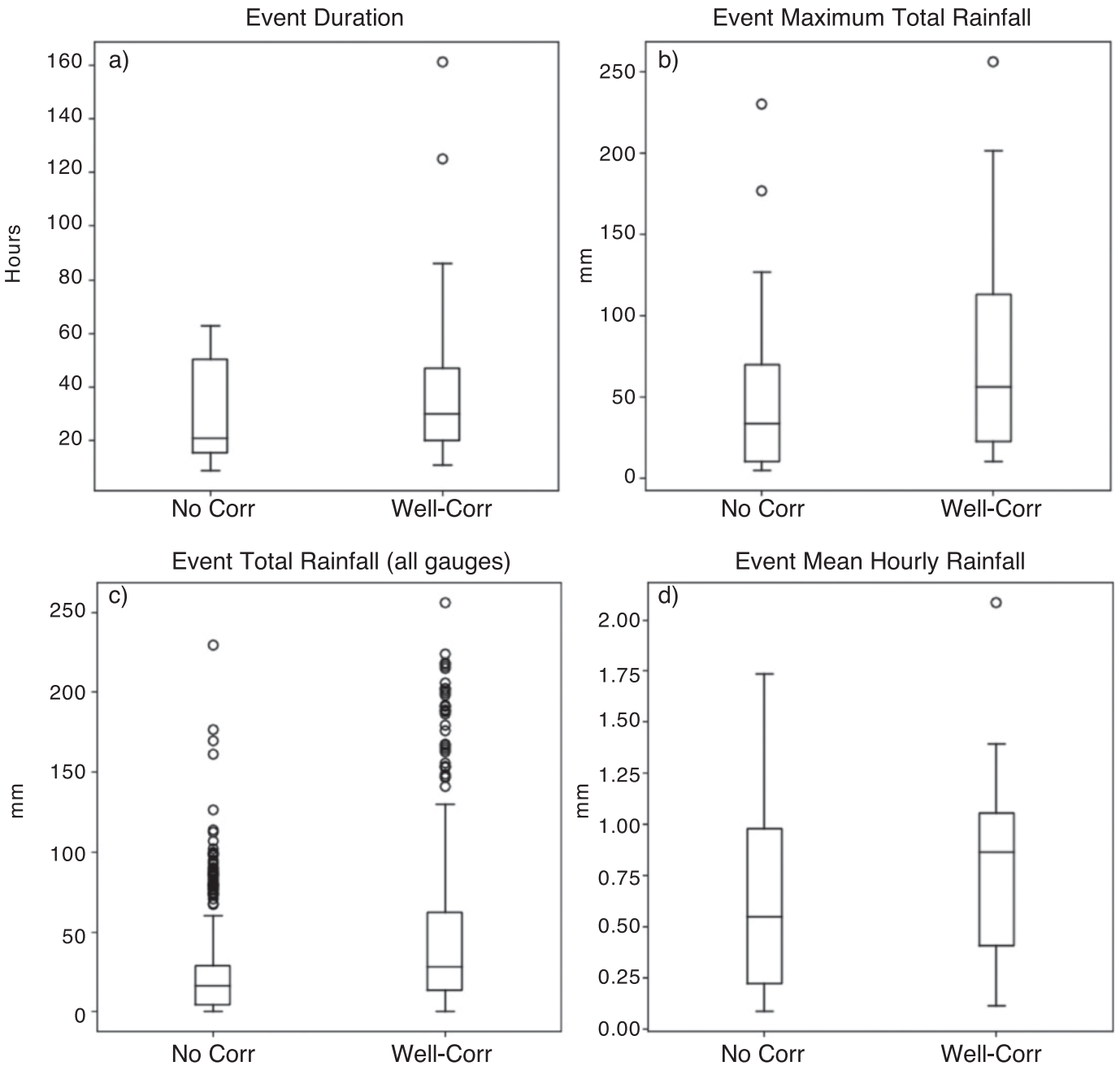

FIG. 3. Event characteristics at HMT gauges for well-correlated and uncorrelated cases: (a) event duration, (b) maximum accumulated rainfall recorded by any gauge within the basin, (c) event total rainfall at all gauge locations, and (d) mean hourly rainfall in the basin during each event. Boxes indicate the IQR, and median is indicated by the horizontal line. Whiskers show the range of the data, with outliers exceeding the 25 th and 75 th percentiles by $1.5 \times$ IQR.

exception of the MRMS-GC at the northern edge of the basin.

For events where MRMS compares poorly to the gauge observations (Figs. 4d-f), the HMT gauges still indicate a maximum of $\sim 0.75$ at MDT, with a secondary maximum of $\sim 0.65$ at gauges located in the terrain to the north, in the Redwood and Potter Valleys (Fig. 4d). With the exception of the MDT site, there appears to be a north to south decrease in accumulated precipitation. This may represent a different spatial distribution of rainfall than the well-correlated cases, or, since elevation increases to the north, it could also be an enhancement of the precipitation-elevation relationship. While the MRMS-MM product indicates a decrease from 0.55 in the north to $\sim 0.3$ in the south (Fig. 4f), the pattern is not nearly as strong as that indicated by the HMT gauges (Fig. 4d). The MRMS-GC product does not capture this distribution at all, showing an even more uniform distribution throughout the basin than for the well-correlated cases (Fig. 4e).

The composites shown in Fig. 4 raise two questions about the spatial distributions of rainfall and the ability of the MRMS products to capture them. First, is the distribution of the uncorrelated cases simply a more longitudinally oriented distribution, or is the northsouth distribution related to an enhancement of the precipitation-elevation relationship? Second, is the favorable comparison between the HMT gauges and 


\section{Well-Correlated Cases}
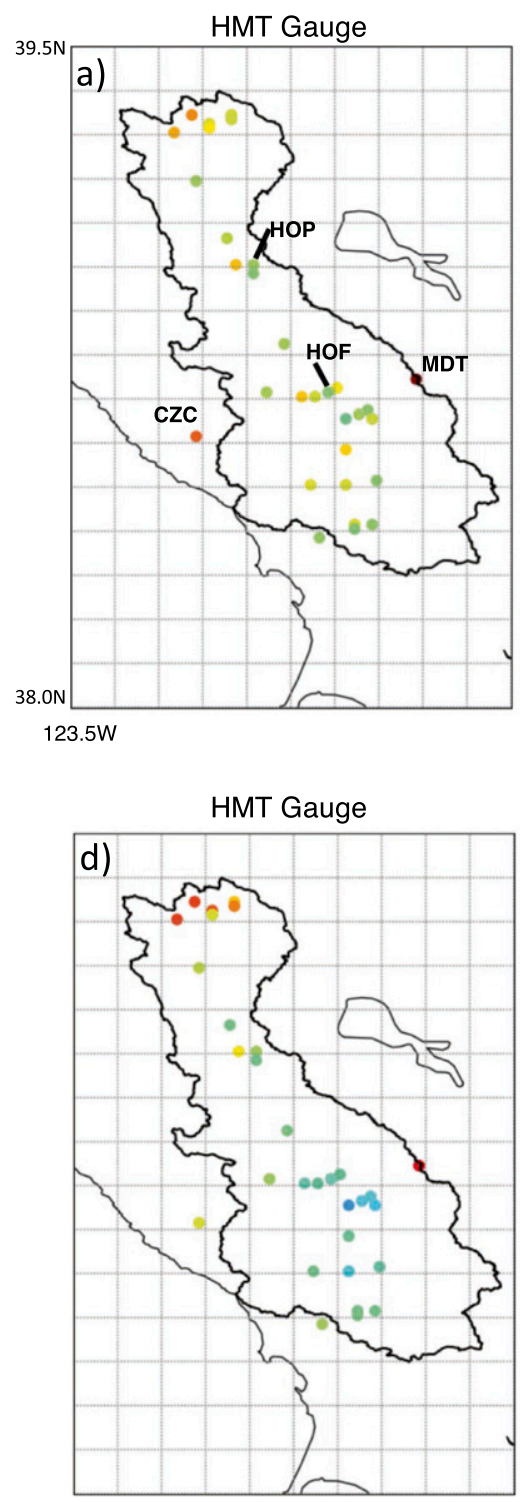

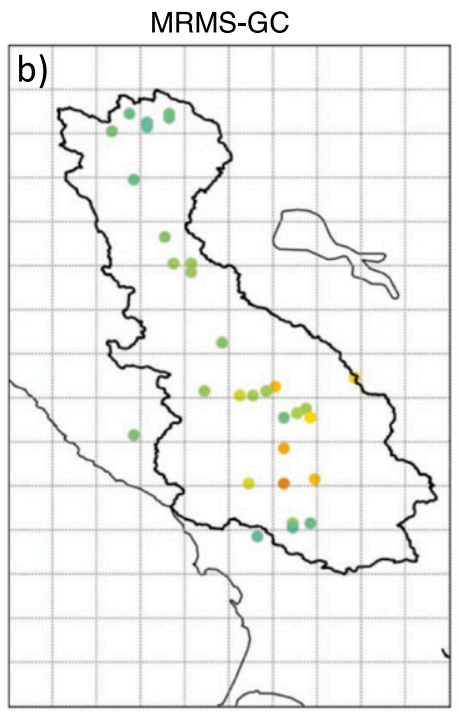

\section{Uncorrelated Cases} MRMS-GC

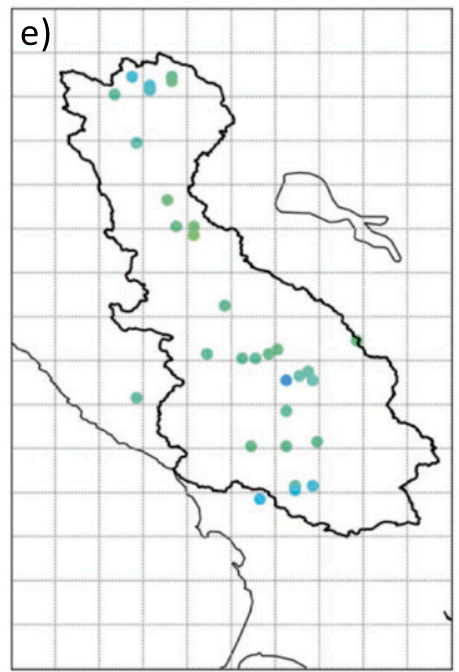

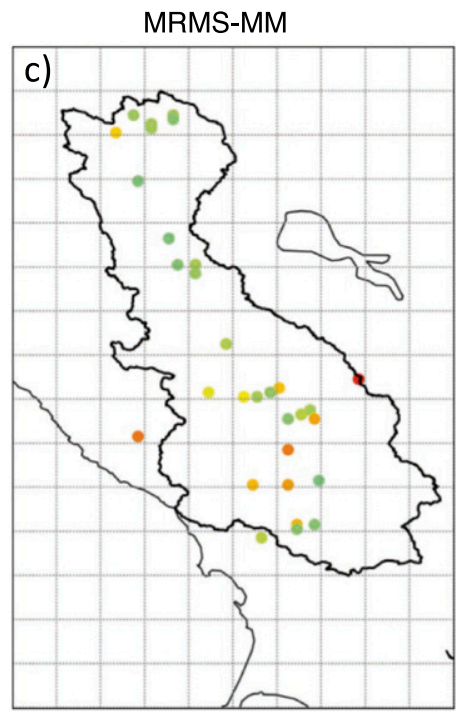

MRMS-MM

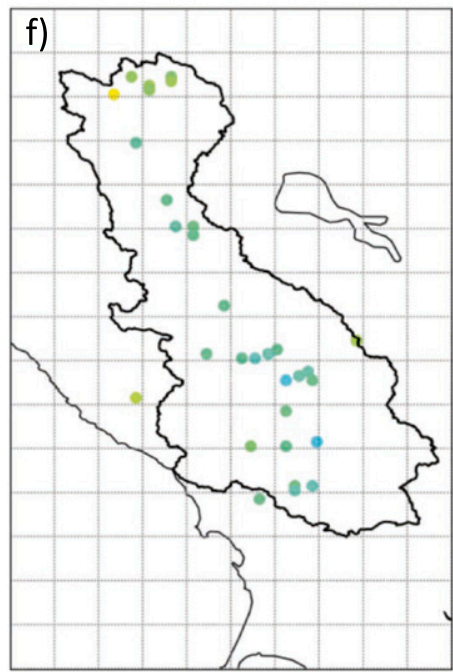

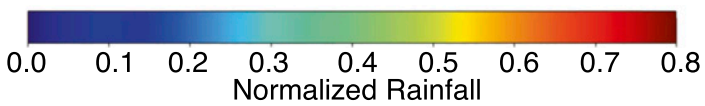

FIG. 4. Composite (average) normalized total rainfall at HMT gauge locations for (a)-(c) well-correlated and (d)-(f) uncorrelated cases from (left) HMT gauges, (center) MRMS-GC, and (right) MRMS-MM.

MRMS-MM in the well-correlated cases due to a precipitation distribution that is more similar to the PRISM climatology (which is used to produce MRMS-MM) than that in the uncorrelated cases? Figures 5 and 6 shed some light on these questions.

Figure 5 shows the mean normalized event total rainfall at gauge locations in 100-m-elevation bins with corresponding linear fits. In the well-correlated cases (Fig. 5a), the MRMS-MM product matches the HMT gauge observations fairly well with a slightly lower slope, while the MRMS-GC product has quite a bit lower slope. For the uncorrelated cases (Fig. 5b), the fit to the HMT gauge observations has both a lower $y$ intercept and a steeper slope, suggesting some strengthening of the precipitation-elevation relationship. In contrast, both the MRMS-MM and MRMS-GC products demonstrate a reduction in the slope of the linear fit compared to the wellcorrelated cases. While the MRMS-MM does still have an 
a)

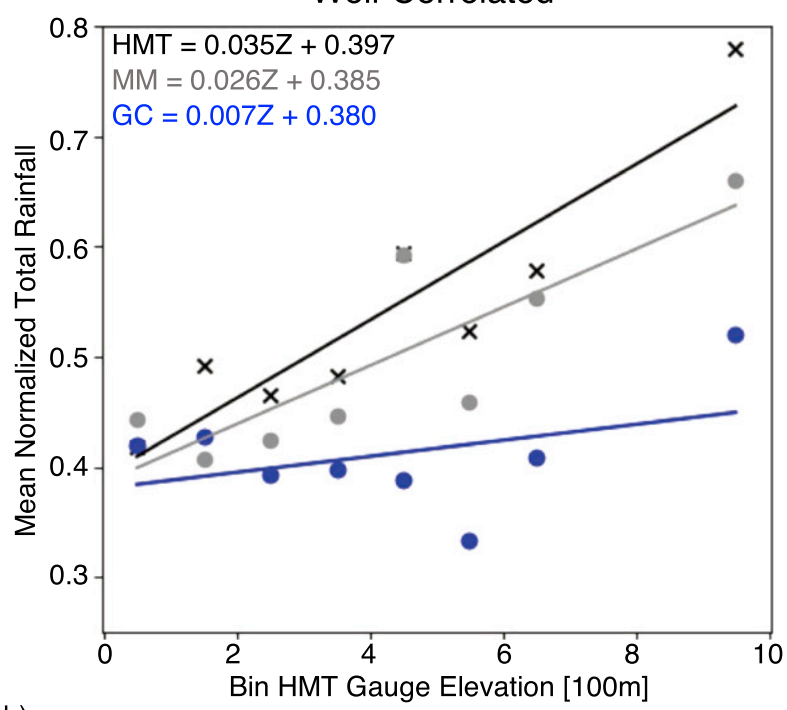

b)

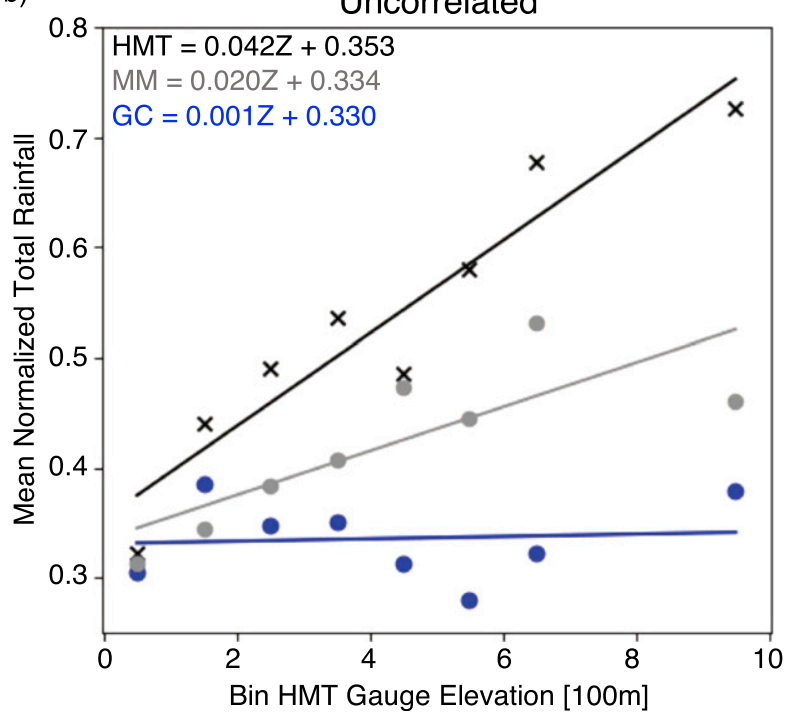

FIG. 5. Average normalized total rainfall in 100-m-elevation bins for (a) well-correlated and (b) uncorrelated events. Linear fits and corresponding equations are shown for HMT gauges (black "X"s), MRMS-MM (gray dots), and MRMS-GC (blue dots).

increase in mean normalized rainfall with elevation, the MRMS-GC product shows practically no relationship.

The similarity between the MRMS-MM and the HMT gauges in the well-correlated cases suggests that the spatial distribution of rainfall during well-correlated cases might be more similar to the spatial distribution of rainfall from the PRISM climatology. Figure 6a shows the average cold season PRISM climatology, calculated using the monthly climatologies from October through March, while Fig. $6 \mathrm{~b}$ shows the average of the normalized monthly climatologies over the same period (calculated by dividing each monthly climatology by the monthly maximum value within the domain). When compared to the composites from the HMT gauges shown in Figs. $4 \mathrm{a}$ and $4 \mathrm{~d}$, the distribution of rainfall during the wellcorrelated cases is more similar to the PRISM climatology than that of the uncorrelated cases. In particular, the PRISM climatology indicates the same high-elevation maxima at MDT and CZC (although CZC has larger values in PRISM), and the same moderate, relatively uniform rainfall through the middle of the basin, particularly in the region between MDT and CZD. While PRISM does indicate some increase in rainfall at the north end of the basin, it is less than that seen in the uncorrelated case composites, and shows the same west to east precipitation gradient through the Redwood and Potter Valleys as the well-correlated HMT gauge composite. Figure $6 \mathrm{c}$ compares the average normalized rainfall at gauge sites during well-correlated and uncorrelated cases to the same from PRISM (i.e., Figs. $4 \mathrm{a}$ and $4 \mathrm{~d}$ vs Fig. 6b). The averaged normalized rainfall at gauge locations compares more favorably to the PRISM climatology during the well-correlated cases, with a correlation of 0.672. During the uncorrelated cases the correlation drops to 0.570 . As Fig. 3 shows, well-correlated cases are typically longer duration events with larger amounts of overall total rainfall, producing an average of $70 \%$ of the rainfall at HMT gauge sites, so it would be expected that these types of cases dominate the climatological distribution.

\section{Discussion}

Examinations of normalized event total rainfall indicate that there are two general categories of storm that impact the Russian River basin during the cold season, and that MRMS QPE products typically more accurately represent the spatial distribution and total amount of rainfall for one type of event over the other (i.e., well-correlated versus uncorrelated cases). In this section, we compare some of the synoptic, mesoscale, and storm-scale characteristics of the two types of storms that occurred during the 2015/16 and 2016/17 seasons.

\section{a. Synoptic patterns}

Composite maps of relevant atmospheric properties were produced for both the well-correlated and uncorrelated events using 6-hourly analysis fields from the ERA-Interim reanalysis (Dee et al. 2011). Composites show the mean conditions over the western United States and eastern Pacific Ocean both prior to and during the events in order to examine the development of the storms.

The most significant difference in the synoptic patterns of the well-correlated and uncorrelated cases is 


\section{PRISM Cool Season Average Rainfall}
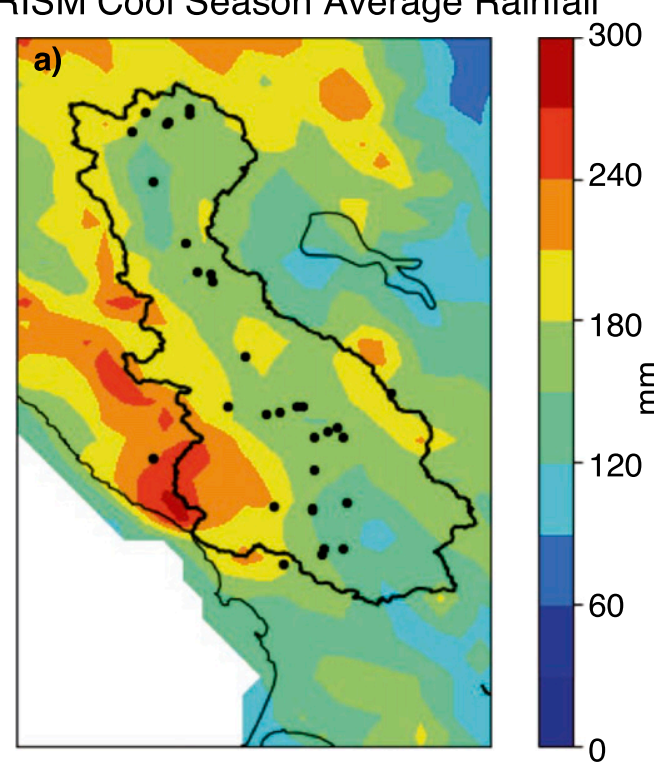

Average Normalized PRISM

Cool Season Rainfall

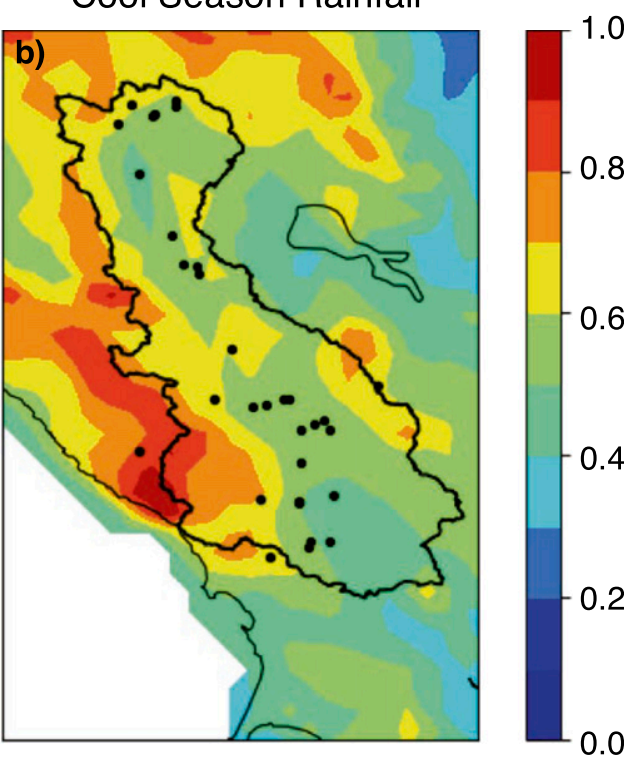

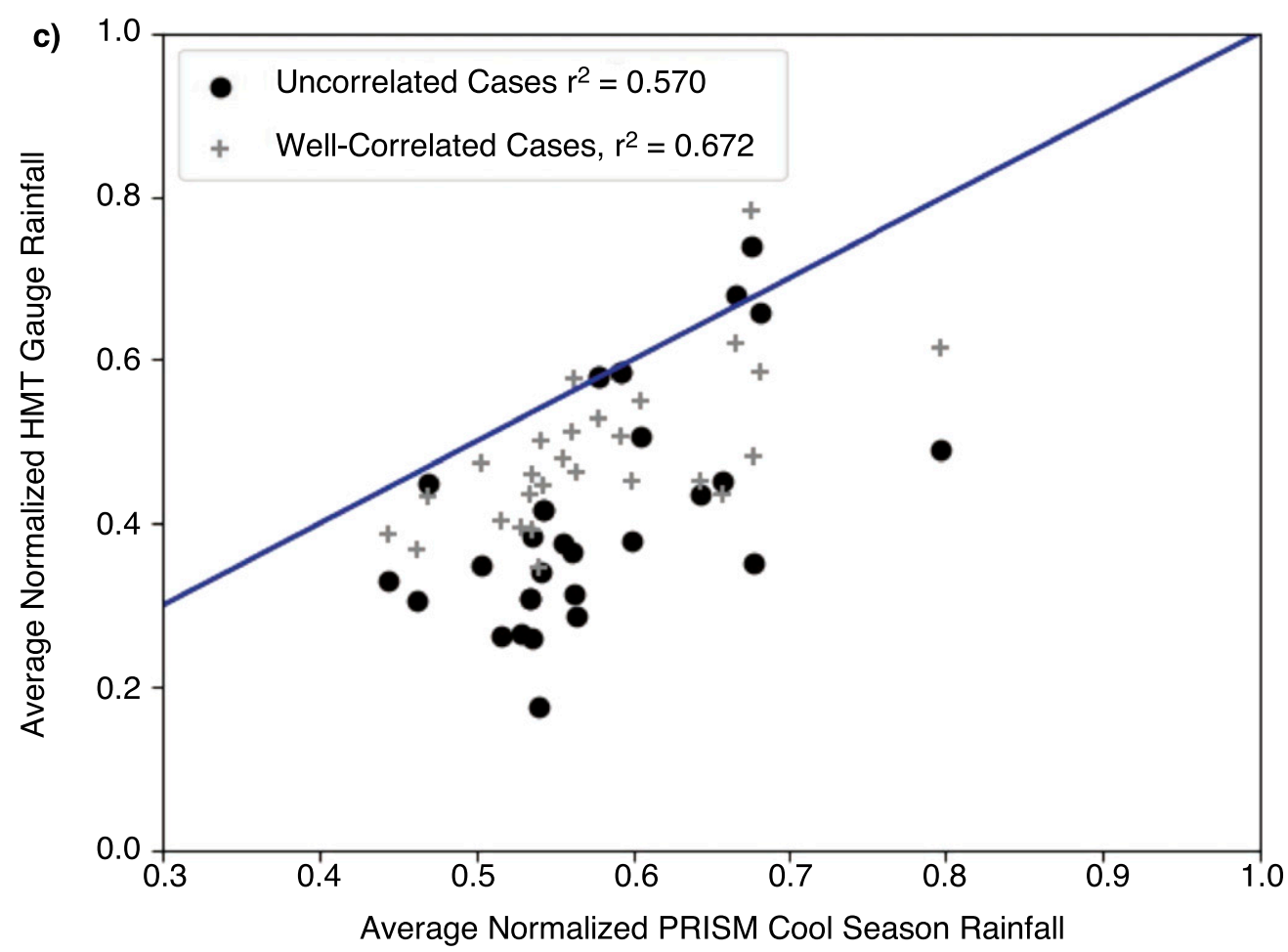

FIG. 6. (a) Average cool season (October-March) rainfall from the PRISM climatology, and (b) the average normalized cool season rainfall. Black dots represent the location of HMT gauges. (c) Comparison of the average normalized PRISM cool season rainfall to the average normalized HMT gauge rainfall for both well-correlated and uncorrelated cases, with the 1-1 line indicated.

found in the MSLP, shown in Fig. 7 at the time of maximum average precipitation in the basin as indicated by the HMT gauges. The well-correlated cases feature a large subtropical high pressure system situated well off the coast, with a trough axis along the coast associated with an extratropical cyclone in the Gulf of Alaska (Fig. 7a). The uncorrelated cases feature a stronger, broader high pressure system extending onshore and 
Composite MSLP at Time of Maximum Basin Average Rainfall
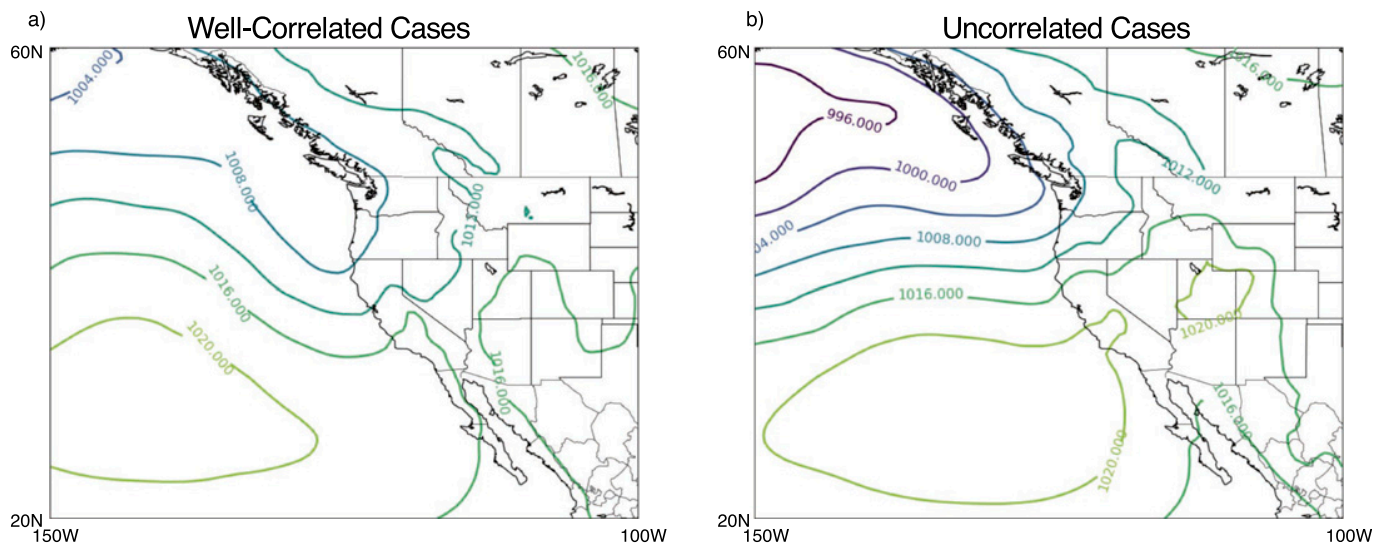

FIG. 7. Composite MSLP (hPa) from ERA-Interim at the time of maximum basin average rainfall for (a) well-correlated and (b) uncorrelated cases.

into the Great basin (Fig. 7b) and a stronger extratropical cyclone in the Gulf of Alaska than that found in the well-correlated cases, producing a larger pressure gradient along the Washington and Oregon coasts and a more zonally oriented trough axis that does not quite make it to the coast of northern California.

The surface pattern is reflected in the $500-\mathrm{hPa}$ geopotential height composites from the same time (Fig. 8), with a 500-hPa trough situated just off the coast during the well-correlated events, and a more zonal pattern impacting coastal California during the uncorrelated cases, which also feature a broader ridge-trough pattern.

The patterns shown in Figs. 7 and 8 compare well to Figs. 6 and 7 from Neiman et al. (2008), who examined 8 years of wintertime (DJF) and summertime (JJA) landfalling ARs along the west coast of North America, categorizing them as making landfall north of $41.0^{\circ} \mathrm{N}$ or making landfall between $32.5^{\circ}$ and $41.0^{\circ} \mathrm{N}$. Though the current study focuses on a longer 6-month cool season as opposed to the 3-month temporal average from Neiman et al. (2008), the surface and 500-hPa synoptic pattern of the well-correlated events shown in Figs. 7 and 8 are very similar to the corresponding wintertime composites for ARs making landfall in the Neiman et al. (2008) southern domain. Similarly, the composite patterns for the uncorrelated events resemble the corresponding Neiman et al. (2008) composites for ARs making landfall in their northern domain.

The IVT composites over the entire duration of the uncorrelated and well-correlated events also share similarities with the north- and south-landfalling ARs discussed in Neiman et al. (2008) and are shown in Fig. 9. In the IVT composites, the uncorrelated cases (Fig. 9b) have a wide swath of IVT exceeding $250 \mathrm{~kg} \mathrm{~m}^{-1} \mathrm{~s}^{-1} \mathrm{im}-$ pacting much of the U.S. West Coast. While there is some increased vapor transport extending into Northern California, the strongest IVT during the uncorrelated cases is concentrated farther north. The composite IVT for the well-correlated cases (Fig. 9a) is more narrow, smaller in magnitude, and the center of the IVT plume impacts the coast somewhat farther south. Compared to the IVT analysis shown in Fig. 3 of Neiman et al. (2008), the uncorrelated case distribution of IVT is quite similar to that of the northward landfalling ARs, which had higher IVT magnitudes than ARs making landfall in their southern domain. While the maximum IVT of $\sim 300 \mathrm{~kg} \mathrm{~m}^{-1} \mathrm{~s}^{-1}$ in the well-correlated case composite appears to be focused somewhat south of the Bay Area, the average IVT in the Russian River basin is similar in the two scenarios $\left(\sim 200 \mathrm{~kg} \mathrm{~m}^{-1} \mathrm{~s}^{-1}\right.$ in the well-correlated cases versus $\sim 230 \mathrm{~kg} \mathrm{~m}^{-1} \mathrm{~s}^{-1}$ for the uncorrelated cases). Ralph et al. (2013) showed that ARs making landfall in DJF had the lowest integrated water vapor of any season, but the strongest upslope wind component and longest duration. In the well-correlated cases, the IVT affecting northern California is more perpendicular to the coastline (and terrain) than in the uncorrelated cases. In well-correlated cases, the strong orographic enhancement over longer storm duration makes up for the lower IVT compared to the uncorrelated cases, resulting in more total rainfall. Furthermore, while cool season rainfall in the Russian River basin is often associated with landfalling ARs, there is potential for non-AR storms to be included in the analysis, which may dilute the north versus south signal in the IVT composites.

The well-correlated and uncorrelated cases also share synoptic-scale similarities with AR events examined by Hecht and Cordeira (2017), who clustered landfalling ARs by their IVT direction and magnitude along the California coast and examine in detail the AR clusters 


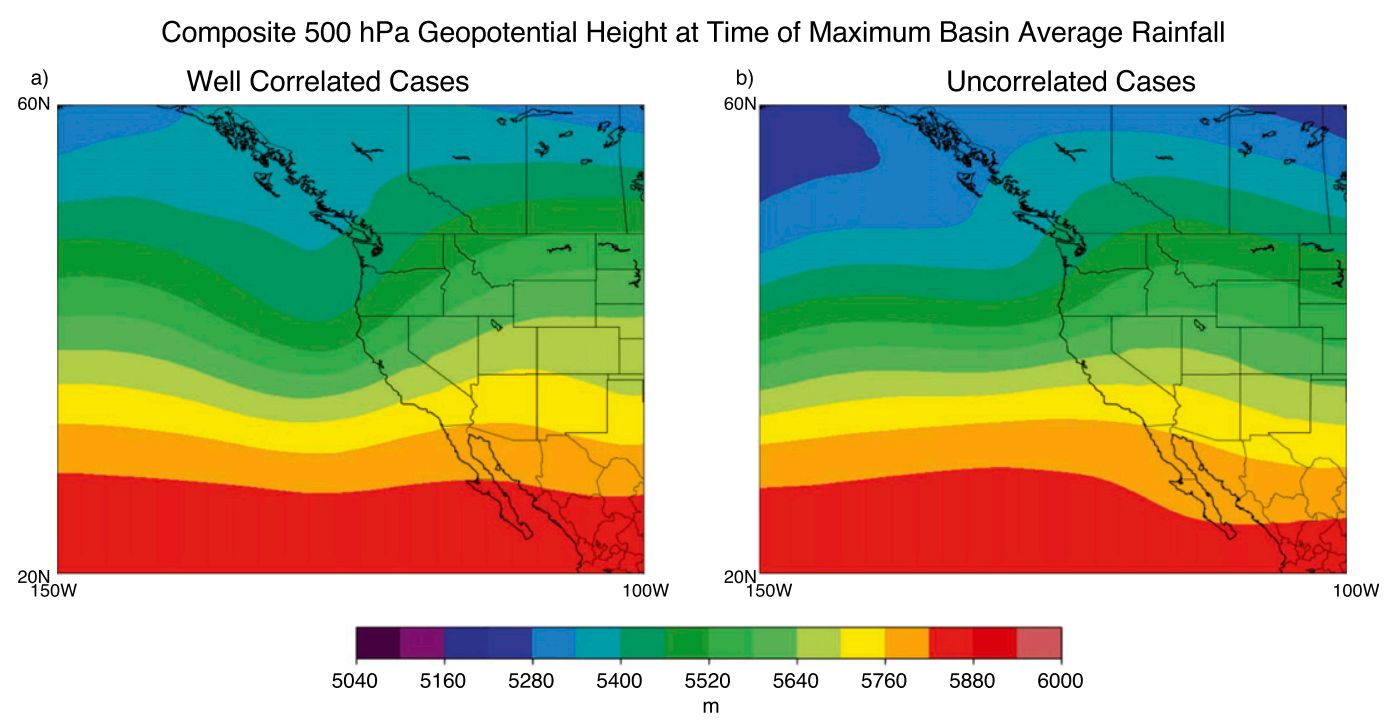

FIG. 8. As in Fig. 7, but for 500-hPa geopotential height (m).

with westerly and south/southwesterly orientations to the coast. Members of the south/southwesterly cluster share similar synoptic conditions and composite rainfall distributions (i.e., relatively widespread) with the wellcorrelated cases discussed herein, while the westerlyoriented cluster has a synoptic setup and north-south decrease in basin precipitation consistent with the uncorrelated cases (their Figs. 2 and 3).

The similarities between the current results and those from previous studies imply that the well-correlated cases are typically associated with ARs that make landfall along the California coast while the uncorrelated events are typically associated with ARs that make landfall farther north. To confirm this hypothesis, 0000 and 1200 UTC analysis fields from the AR Detection Tool (ARDT; Wick et al. 2013; https://www.esrl.noaa.gov/psd/ psd2/coastal/satres/data/html/ar_detect_gfs.php) were examined to subjectively determine if and where ARs made landfall during each of the 44 events considered in this study. The ARDT uses GFS model output of TPW and IVT to identify the presence and axis of ARs in the eastern Pacific. The use of GFS model output results in fairly coarse temporal resolution, and therefore some cases' landfall could not be determined because it may have occurred between model runs. Figure 10 shows how many well-correlated and uncorrelated cases

\section{Composite IVT Through Duration of Events}

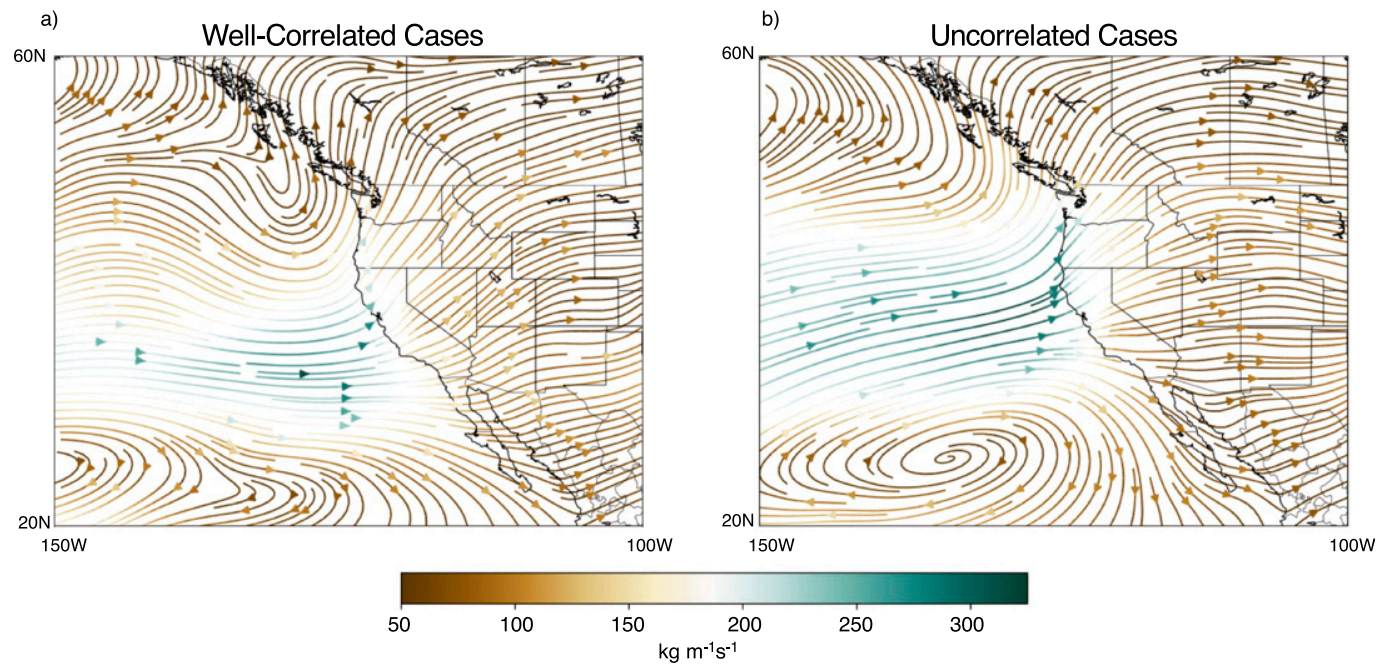

FIG. 9. As in Fig. 7, but for IVT $\left(\mathrm{kg} \mathrm{m}^{-1} \mathrm{~s}^{-1}\right)$ over the entire duration of the cases. 


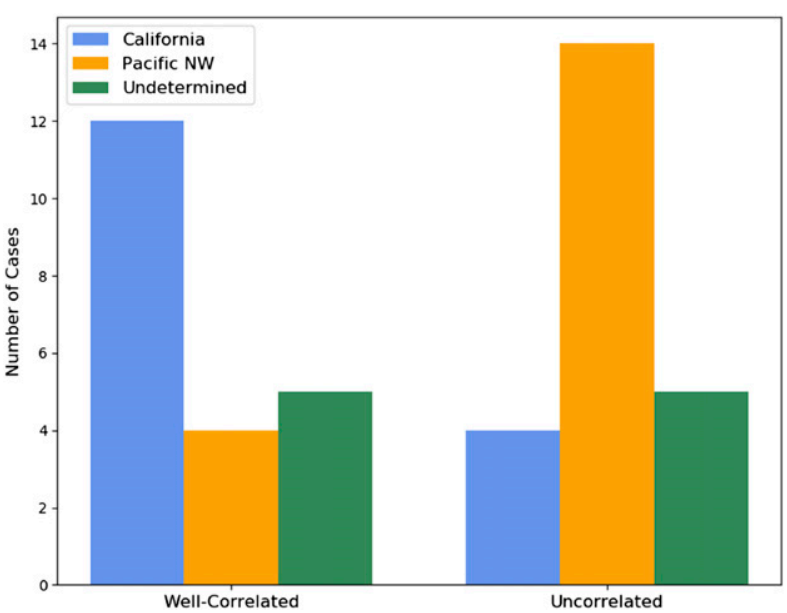

FIG. 10. Number of well-correlated and uncorrelated events determined to have made landfall along the coast of California, the Pacific Northwest, or that could not be determined using the ARDT.

were classified using the ARDT as landfalling in California, landfalling in the Pacific Northwest, or undetermined, and indicates that there is some support for the hypothesis that well-correlated events feature ARs that make landfall along the California coast, while uncorrelated events are more often associated with ARs making landfall along the Pacific Northwest coast.

The similarities between the composite conditions discussed above and those shown in Neiman et al. (2008) and Hecht and Cordeira (2017), combined with the results from the ARDT suggest that, in the Russian River Valley, the MRMS QPE products are typically more reliable during $\mathrm{AR}$ events that make landfall at or near the California coastline, but less reliable during AR events that make landfall farther north. Since much of the rainfall during the cool season is associated with ARs and more rain is likely when the associated plume of moisture encounters more orographic forcing, the PRISM climatology would likely be more similar to these types of systems, resulting in MRMS-MM QPEs that compare more favorably to the HMT gauges under such conditions. The rainfall occurring as a result of ARs making landfall farther north near the Canadian border would likely be more transient and disorganized since it is associated with the outer reaches of its parent moisture plume. With the main corridor of IVT to the north, it would also make sense to see rainfall decreasing toward the south as is found in the uncorrelated cases.

The distribution of rainfall within the basin and synoptic setups that produce events that are more similar to the PRISM climatology provide good evidence as to why the MRMS-MM product more closely matches the HMT gauges during these events than it does for the cases that appear to be a result of ARs affecting the
Pacific Northwest. The MRMS-GC product is not dependent on climatology, however, and we therefore look to smaller scales to gain insight to its performance.

\section{b. Mesoscale winds}

At the basin scale, terrain interaction likely influences the spatial distribution of precipitation. Because ERAInterim has relatively coarse resolution, we use the RTMA (De Pondeca et al. 2011) at $2.5-\mathrm{km}$ resolution to examine the $10-\mathrm{m}$ winds in the Russian River basin at the time of maximum basin average rainfall (Fig. 11). Wind barbs are overlaid on the terrain, with the Russian River basin outlined. Barbs represent 1/10 the standard values (i.e., $0.5,1.0$, and $5.0 \mathrm{~m} \mathrm{~s}^{-1}$ ). Although the RTMA data is $2.5-\mathrm{km}$ resolution, wind barbs are plotted every $\sim 10 \mathrm{~km}$ for easier viewing (Figs. 11a,c), and at the gauge locations to highlight possible small-scale terrain interaction affecting measured precipitation at the gauges (Figs. 11b,d)

At the time of maximum rainfall intensity in the basin, offshore winds are south-southwesterly in the wellcorrelated cases and southerly in the uncorrelated cases with intensities of $5+\mathrm{m} \mathrm{s}^{-1}$ (Figs. 11a,c). These winds extend onshore and into the southern part of the basin through a relative low spot in the terrain. In the well-correlated cases, winds entering the southern edge of the basin are 1-2 $\mathrm{m} \mathrm{s}^{-1}$ stronger than in uncorrelated cases, potentially transporting more moisture inland from the coast. These winds converge with slower winds near Healdsburg (HOF in Fig. 1a), possibly contributing to somewhat enhanced rain rates through this part of the basin as seen in Fig. 4a. In contrast, $1-1.5 \mathrm{~m} \mathrm{~s}^{-1}$ winds entering the southern part of the basin during the uncorrelated cases encounter divergence near HOF, where winds increase to $2.5-3 \mathrm{~m} \mathrm{~s}^{-1}$, which may contribute to the lighter rainfall seen in this region in Fig. $4 \mathrm{~d}$.

Through the narrowest portion of the basin, winds in both the well-correlated and uncorrelated events feature downslope from the western rim, upslope on the eastern edge, and up-valley flow through the middle. However, farther north the two patterns again differ. In the wellcorrelated cases the southerly up-valley flow remains, resulting in generally weak orographic enhancement at the northernmost gauge sites. In the uncorrelated cases a more westerly flow prevails, which may result in stronger orographic precipitation enhancement as it encounters both the ridge dividing the Redwood and Potter Valleys and the more significant terrain increases to the east of the basin. This pattern is most apparent when viewing winds at the individual gauge locations in Figs. 11b and $11 \mathrm{~d}$.

The interaction of the near-surface flow with smallscale terrain features appears to have the expected 


\section{Time of Maximum Basin Average Precipitation}

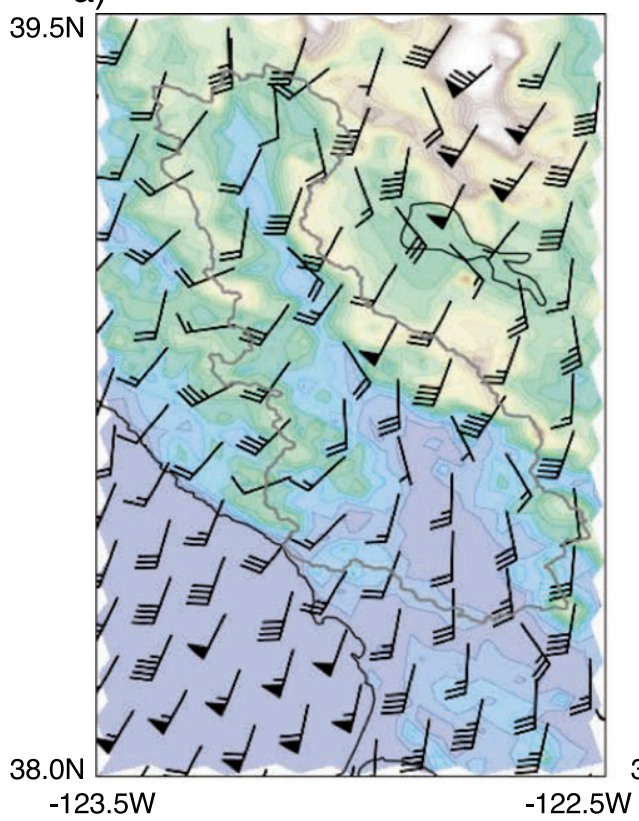

b) Well-correlated Cases

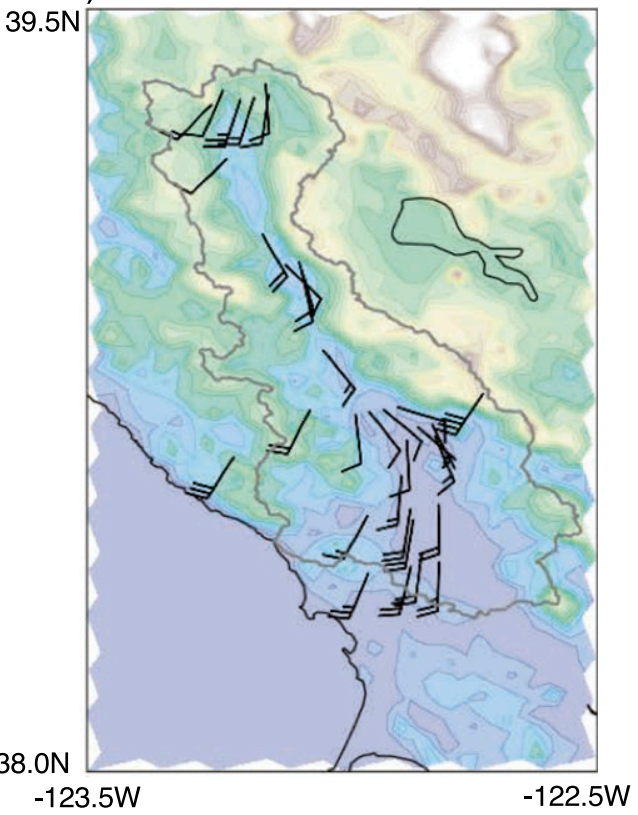

c) Uncorrelated Cases

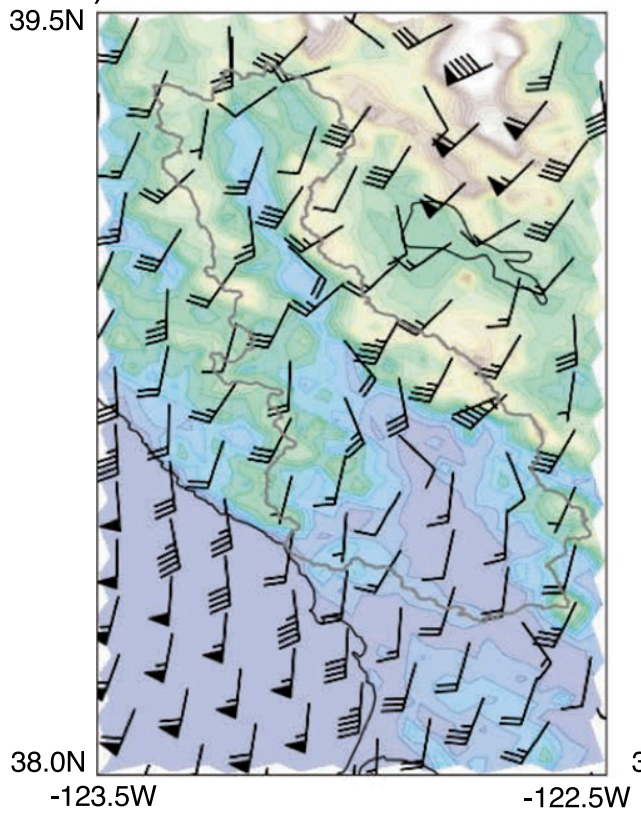

d) Uncorrelated Cases

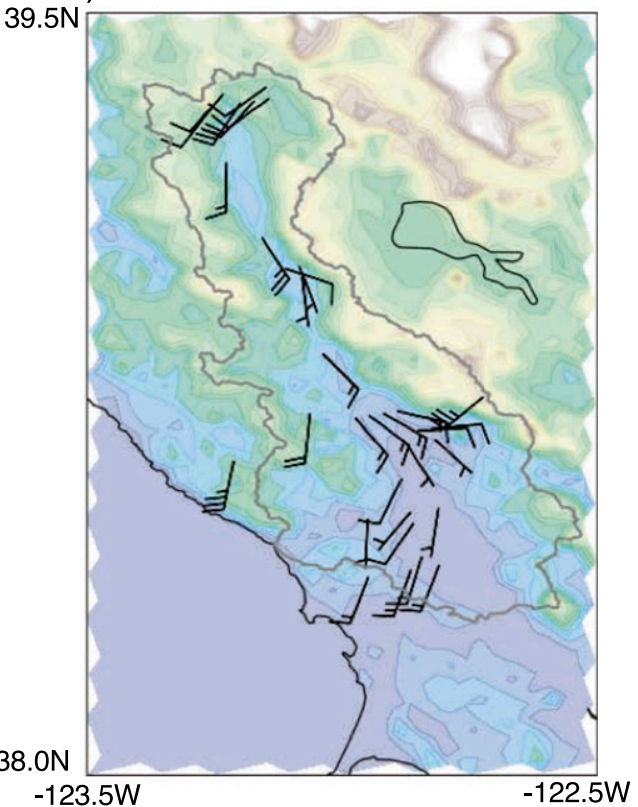

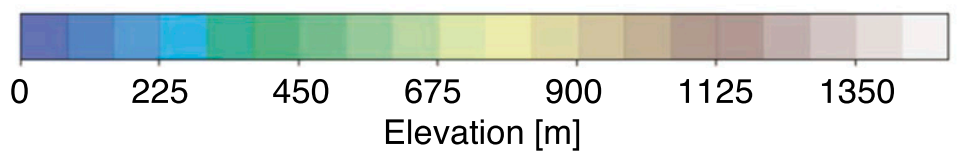

FIG. 11. RTMA 2.5-km gridded 10-m wind composites at the time of maximum basin average rainfall for (a) well-correlated and (c) uncorrelated cases. (b),(d) As in (a) and (c), but for gauge locations only. Barbs represent $1 / 10$ the standard values (i.e., $0.5,1.0$, and $5.0 \mathrm{~m} \mathrm{~s}^{-1}$ ), and color shading indicates elevation. 

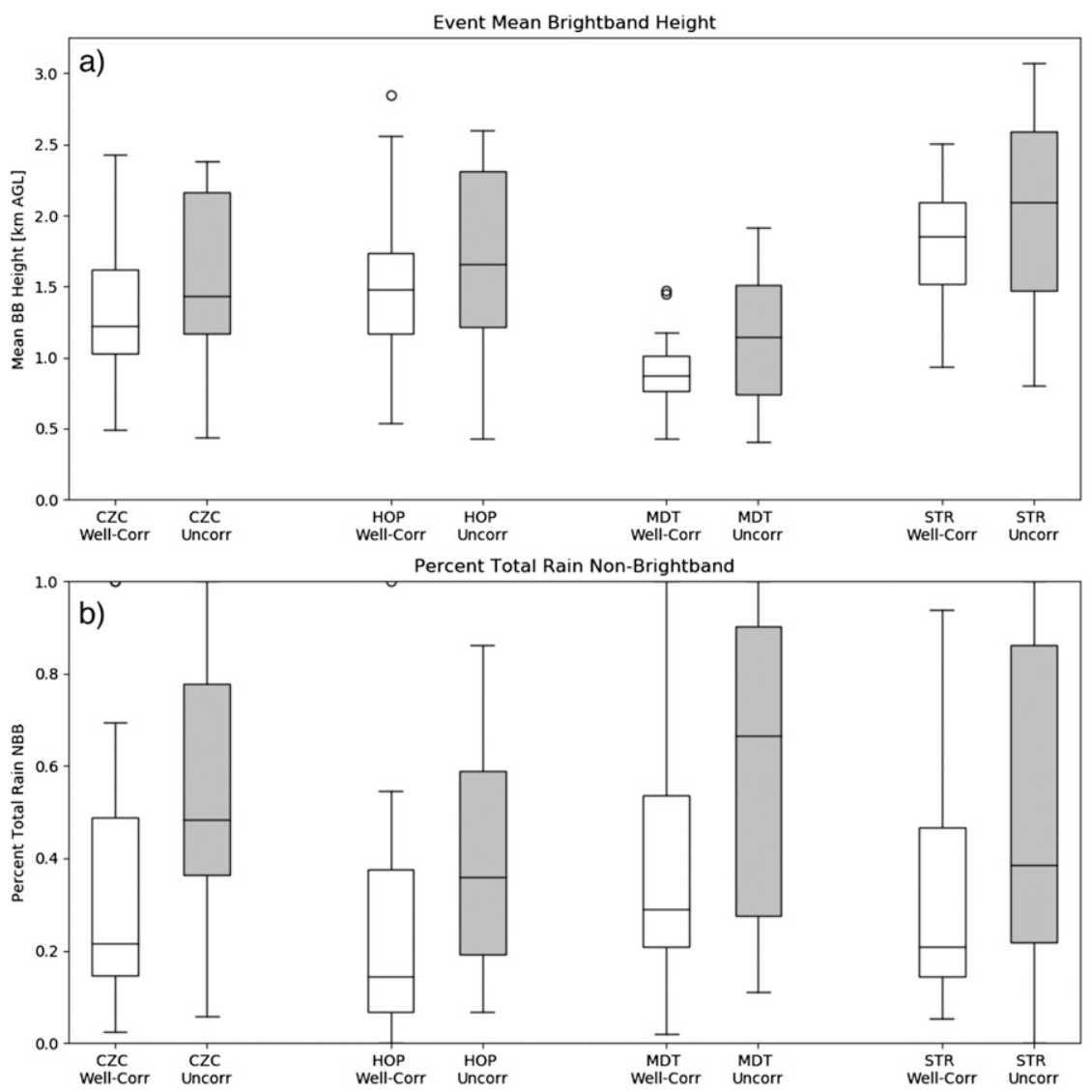

FIG. 12. Box-and-whisker plots (as in Fig. 3) for (a) mean brightband height (km AGL) and (b) the percent of total rainfall that fell as NBB rain for both well-correlated (white) and uncorrelated (gray) cases at the four HMT profiling radar sites.

effects given our understanding of orographic precipitation enhancement. Small-scale shifts in airflow can result in gauges in close proximity to one another receiving widely varying rainfall amounts. It is possible that these small-scale variations could invalidate the typical inverse distance weighting functions used to interpolate the HADS gauge data to the MRMS grid. The MRMS-GC product is also highly dependent on radar, even in regions where the radar may not be completely reliable. Therefore, in the next section we examine data from the four profiling radars at the CZC, MDT, HOP, and STR HMT gauge sites.

\section{c. Storm scale}

While the four profiling radars operated by PSD in and near the Russian River basin can be used to compare instantaneous rain rates and vertical profiles of reflectivity with WSR-88D pixels in the same location, we continue assessing the two categories of events in a more composite sense, using the data to determine the presence and height of a reflectivity bright band. As discussed, the nearest operational weather radar to the Russian River Valley is over $100 \mathrm{~km}$ away, and the lowest-elevation scan angle is mostly blocked by the terrain. This complicates radar-based QPEs in the basin, as the beam either intersects the storm at or above the bright band so the observed reflectivity is not representative of surface rainfall, or the beam is sufficiently high off the ground to miss shallow rainfall entirely. The MRMS radar-based QPE algorithm automatically accounts for intersection with the upper levels of the storm with an apparent vertical profile of reflectivity (VPR) correction (Zhang et al. 2016), but the latter issue lacks a feasible solution. The presence of a bright band and an estimate of its height within the storm can provide some insight into the type of precipitation falling and whether we expect the WSR-88D to capture it.

Figure 12 displays box-and-whisker plots (as in Fig. 3) of the mean hourly height (km AGL) of the bright band (when present) and the percent of event total rainfall that occurred in the absence of a bright band [i.e., nonbrightband (NBB) rain; White et al. 2003] at each of the profiling radar locations for the well-correlated and uncorrelated events. 

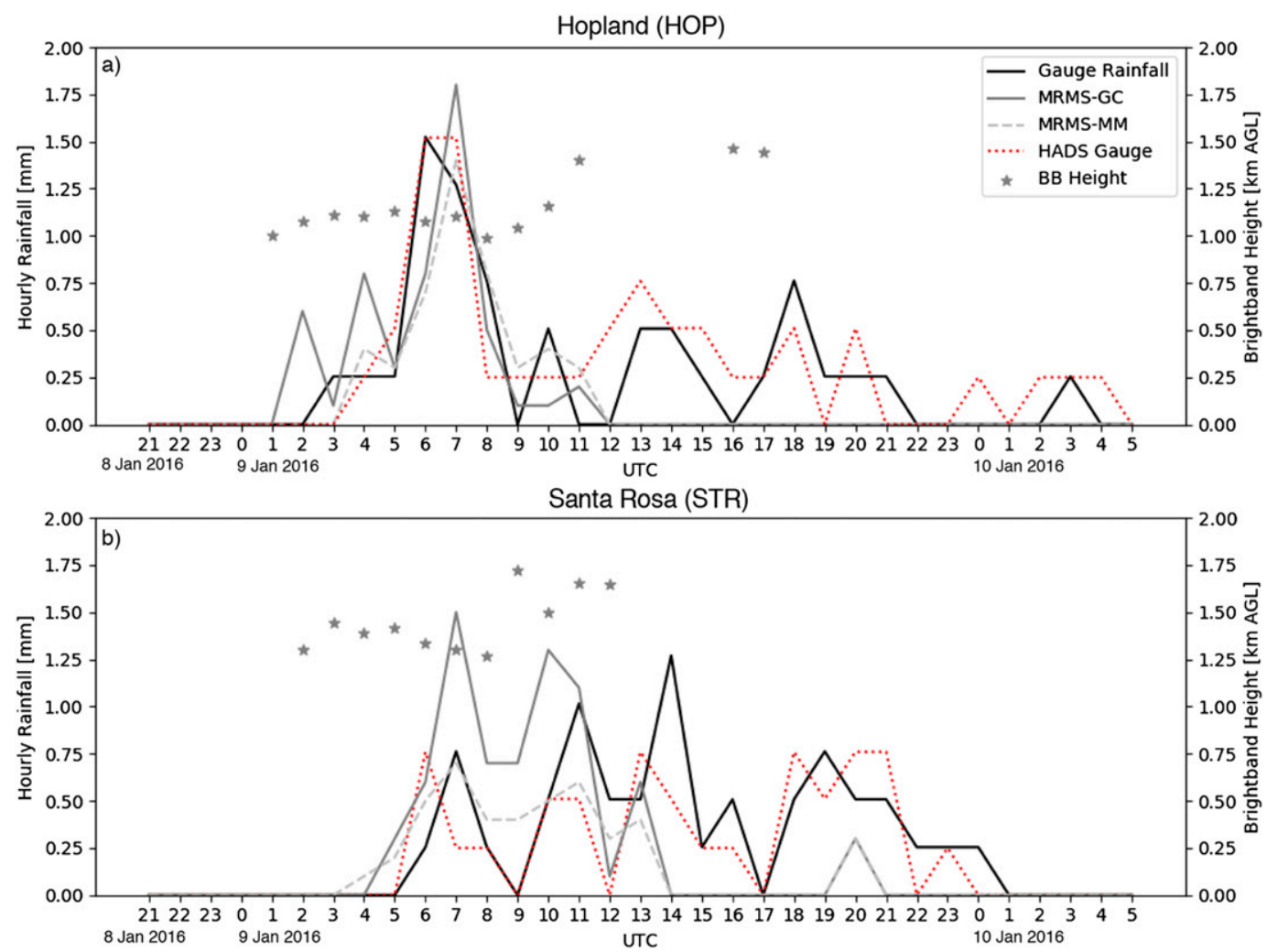

FIG. 13. Hourly rainfall from HMT gauges (black), MRMS-GC (gray solid), MRMS-MM (gray dashed), and nearby HADS gauges (red dotted) at (a) Hopland and (b) Santa Rosa. Stars indicate the height of the bright band detected by the HOP and STR profiling radars.

Figure 12a shows that median brightband heights are typically between 1 and $2 \mathrm{~km} \mathrm{AGL}$, and that wellcorrelated cases have lower median brightband heights with smaller IQR than uncorrelated cases. The two operational radars closest to the basin are KDAX to the east and San Francisco, California (KMUX), to the south. The lowest elevation scan of KMUX is more than $3 \mathrm{~km}$ AGL over the basin, significantly higher than the median brightband heights for all cases at each profiler site. White et al. (2003) cite a February 1998 case in which the KMUX radar completely overshot a shallow precipitating system that produced significant rainfall in Cazadero, however Matrosov et al. (2014) found that in the event of deeper precipitating systems, KMUX may observe precipitation in higher regions of the storm and provide reasonable QPE after an appropriate VPR correction is applied. The lowest scan of the KDAX radar is approximately $1 \mathrm{~km}$ AGL in the basin, but is mostly blocked by the terrain (Fig. 1b). Where the lowest scan from the KDAX radar is unobstructed, there is a good chance of observing brightband precipitation in the Russian River basin.

Perhaps the most telling result from Fig. 12 is that the uncorrelated cases typically receive a much larger percentage of their total rainfall from NBB rain than the well-correlated cases (Fig. 12b). When combined with the height of the radar beams, the significant fraction of NBB rain observed during the uncorrelated cases suggests storms with a significant portion of their rainfall unobserved by the radar, consistent with Matrosov et al.'s (2014) finding that $30 \%$ of the hours experiencing NBB rain at Cazadero were not detected by the operational radars. Since the MRMS algorithm uses radar to QC the HADS gauges when RQI is greater than 0.1, gauge observations correctly identifying rainfall are potentially being discarded when the radar senses above the storm and indicates zero precipitation, resulting in significant underestimation in the MRMS-GC product. The MRMS-MM product does not exhibit as much degradation in quality as the MRMS-GC because the adjustment for elevation partially mitigates the reduced gauge influence.

Figure 13 shows an example of this phenomenon during an uncorrelated case at two profilers [Hopland (Fig. 13a) and Santa Rosa (Fig. 13b)] that have a HADS gauge located nearby. Hourly rainfall from the HMT and HADS gauges as well as the MRMS-MM and MRMS-GC is shown beginning at 2100 UTC 8 January 2016 and ending at 0500 UTC 10 January 2016. Hourly 

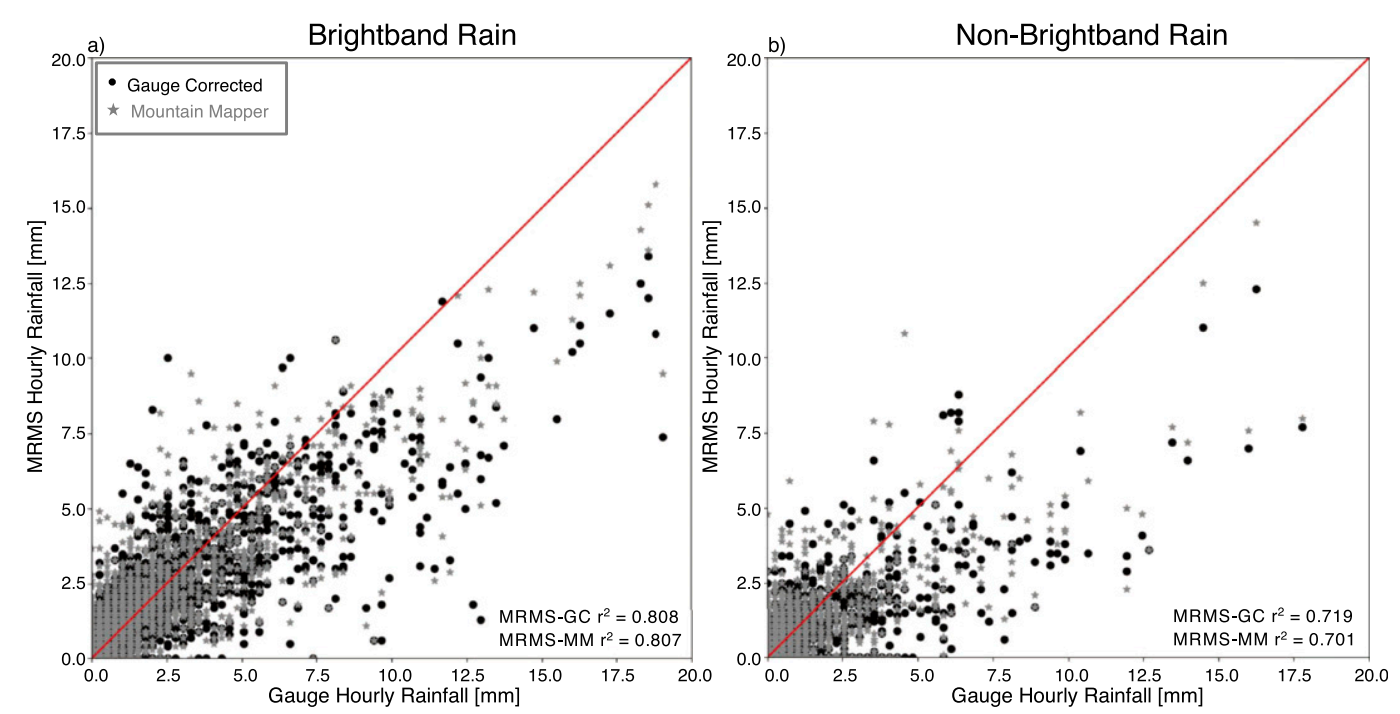

FIG. 14. Hourly precipitation estimates for all cases at the four HMT gauge sites collocated with a profiling radar for (a) hours when a bright band was detected and (b) hours with no bright band.

mean brightband height from the collocated profiling radar is also shown. The Hopland profiler detects a bright band starting at 0100 UTC 9 January and the MRMS-GC begins indicating rainfall an hour before the HMT gauge and $2 \mathrm{~h}$ before either the MRMS-MM or the HADS gauge. After 1200 UTC 9 January, the profiler indicates the presence of a bright band for only $2 \mathrm{~h}$. While both gauges continue to measure precipitation during this time, neither MRMS product shows any accumulation for the remainder of the event. Similarly, at Santa Rosa, both MRMS products indicate precipitation during most of the hours when a bright band is observed, with the MRMS-GC estimating nearly twice as much hourly rainfall as the products with no radar influence. No bright band is detected after 1300 UTC 9 January and while the gauges accumulate several millimeters of rainfall during the remainder of the event, the MRMS products show less than $0.5 \mathrm{~mm}$ falling after this time. Figure 14 compares hours identified as having either brightband or non-brightband rain at the four profiling radar sites. Mean hourly rainfall at HMT gauges for hours with a detected bright band is $1.69 \mathrm{~mm}$ and is $0.54 \mathrm{~mm}$ during hours with NBB rain. Biases for the MRMS-MM and MRMS-GC are $-12 \%$ and $-6 \%$, respectively, during hours when a bright band was detected. During hours with NBB rain, the MRMS-GC bias is $-39 \%$ and the MRMS-MM bias is $-17 \%$.

\section{Summary and conclusions}

In this study we identified 44 precipitating events in the Russian River basin during the 2015/16 and 2016/ 17 wet seasons. Event total QPE from two MRMS products, the gauge-corrected radar and Mountain Mapper, was compared to the relatively dense network of HMT gauges. The HMT gauges were subjected to manual quality control and are independent of the gauge networks used to create the MRMS products. With respect to the HMT gauges, the MRMS products captured event total rainfall with varying degrees of accuracy, but generally either captured the spatial distribution and intensity of rainfall fairly well (i.e., well-correlated), or captured neither the spatial distribution nor had much variability within the basin (i.e., uncorrelated). For the well-correlated cases, the composite spatial distribution of rainfall from the HMT gauges showed a fairly moderate distribution of rainfall with terrain-induced maxima similar to the PRISM climatology, and showed a north-to-south decrease in precipitation within the basin for the uncorrelated cases. Because of the general decrease in elevation from the source of the Russian River in the north toward the mouth in the south, it appears this may be due to an enhancement in the climatological orographic influence on precipitation amount, but it is difficult to definitively determine if this is the case.

There are a number of intricacies to rainfall behavior in the Russian River basin, and no two events are alike. However, by looking at composite behavior over a number of events, we can gain some understanding of the general behavior of MRMS QPEs during different types of storm systems. By examining the composite atmospheric properties at a variety of scales for the two types of cases, it is inferred that the performance of the MRMS in the Russian River basin is affected by the location of AR landfall, specifically whether the event was associated with an AR making landfall on the 
California coast, or farther north along the coast of Washington, Oregon, or British Columbia. ARs making landfall along the California coast typically resulted in a spatial distribution of rainfall more similar to the PRISM climatology, while those making landfall farther north produced a more north-south gradient in precipitation. This affects the applicability of the PRISM precipitation-elevation adjustment used in the MRMSMM products.

At the basin scale, the two types of systems showed near-surface wind patterns featuring small-scale areas of convergence, divergence, and terrain interactions that likely contributed to the differing spatial distributions of the precipitation and level of similarity with the PRISM climatology. Profiling radar observations at four HMT gauge sites indicated that a larger fraction of the precipitation during uncorrelated events fell as NBB rain that may have been undetected by operational radars, in turn reducing the amount of precipitation estimated to have fallen by the MRMS-GC. The specific mechanisms related to the synoptic- and basin-scale patterns that produce the differing storm characteristics (BB versus NBB rain) is reserved for future work.

Understanding the reliability of MRMS products with regard to larger-scale storm patterns can be helpful to hydrologists and water managers requiring accurate QPEs. For example, in both event types, the MRMS-MM more closely matched the HMT gauges than the MRMS-GC, consistent with results found by Schaake et al. (2004), Zhang et al. (2014), and Zhang et al. (2016). This may be important for future implementations of the NOAA National Water Model, which currently uses a combination of MRMS radar-only and MRMS-GC in its analysis cycle. Additionally, the insight gained in this study can be applied to studies of QPEs in other basins and larger areas, particularly where the radar may be more or less reliable under certain conditions or where some storms may not exhibit climatological precipitation-elevation relationships.

Acknowledgments. This work supported by the NOAA Physical Sciences Division. HMT gauge and profiler data are available from www.esrl.noaa.gov/psd/data/obs/ datadisplay/. MRMS data are available at https://www. nssl.noaa.gov/projects/mrms/. ARDT Detection tool images are found at https://www.esrl.noaa.gov/psd/psd2/ coastal/satres/ar_detect.html. ERA-Interim data were acquired from https://www.ecmwf.int/en/forecasts/datasets/ reanalysis-datasets/era-interim and RTMA reanalysis data were acquired at http://www.nco.ncep.noaa.gov/pmb/ products/rtma. Many thanks to Dr. Haonan Chen for providing code to calculate beam blockage ratio to produce figure Figs. $1 \mathrm{~b}$ and $1 \mathrm{c}$, as well as his valuable commentary during internal review.

\section{APPENDIX}

\section{List of Acronyms}

AGL Above ground level

AR Atmospheric river

ARDT Atmospheric River Detection Tool

CONUS Continental United States

DEM Digital elevation model

ESRL Earth System Research Laboratory

HADS Hydrometeorological Automated Data

System

HMT Hydrometeorology Testbed

IQR Interquartile range

IVT Integrated vapor transport

MRMS Multi-Radar/Multi-Sensor

MRMS-GC Gauge-corrected MRMS

MRMS-MM MRMS Mountain Mapper

MSL Mean sea level

MSLP Mean sea level pressure

NBB Non-bright band

NCEP National Centers for Environmental

Prediction

NOAA National Oceanographic and Atmospheric Administration

NWS National Weather Service

PRISM Parameter-Elevation Regressions on Independent Slopes Model

PSD Physical Sciences Division

QC Quality control

QPE Quantitative precipitation estimation

RRHBN Russian River Habitat Blueprint Network

RQI Radar Quality Index

RTMA Real-Time Mesoscale Analysis

RUC Rapid Update Cycle

TPW

VPR

Vertical profile of reflectivity

\section{REFERENCES}

Biemans, H., R. W. A. Hutjes, P. Kabat, B. J. Strengers, D. Gerten, and S. Rost, 2009: Effects of precipitation uncertainty on discharge calculations for main river basins. J. Hydrometeor., 10, 1011-1025, https://doi.org/10.1175/2008JHM1067.1.

Blenkinsop, S., E. Lewis, S. C. Chan, and H. J. Fowler, 2017: Quality-control of an hourly rainfall dataset and climatology of extremes for the UK. Int. J. Climatol., 37, 722-740, https:// doi.org/10.1002/joc. 4735 .

Ciach, G. J., 2003: Local random errors in tipping-bucket rain gauge measurements. J. Atmos. Oceanic Technol., 20, 752-759, https:// doi.org/10.1175/1520-0426(2003)20<752:LREITB > 2.0.CO;2.

Cordeira, J. M., F. M. Ralph, A. Martin, N. Gaggini, J. R. Spackman, P. J. Neiman, J. J. Rutz, and R. Pierce, 2017: Forecasting atmospheric rivers during Calwater 2015. Bull. 
Amer. Meteor. Soc., 98, 449-459, https://doi.org/10.1175/ BAMS-D-15-00245.1.

Daly, C., R. P. Neilson, and D. L. Phillips, 1994: A statisticaltopographic model for mapping climatological precipitation over mountainous terrain. J. Appl. Meteor., 33, 140-158, https://doi.org/ 10.1175/1520-0450(1994)033<0140:ASTMFM > 2.0.CO;2.

—, M. E. Slater, J. A. Roberti, S. H. Laseter, and L. W. Swift Jr., 2017: High-resolution precipitation mapping in a mountainous watershed; Ground truth for evaluating uncertainty in a national precipitation dataset. Int. J. Climatol., 37, 124-137, https://doi.org/10.1002/joc.4986.

Dee, D. P., and Coauthors, 2011: The ERA-Interim reanalysis, configuration, and performance of the configuration system. Quart. J. Roy. Meteor. Soc., 137, 553-597, https://doi.org/ 10.1002/qj.828.

De Pondeca, M. S. F. V., and Coauthors, 2011: The Real-time mesoscale analysis ad NOAA's National Centers for Environmental Prediction: Current status and development. Wea. Forecasting, 26, 593-612, https://doi.org/10.1175/WAF-D-10-05037.1.

Dettinger, M. D., F. M. Ralph, T. Das, P. J. Neiman, and D. R. Cayan, 2011: Atmospheric rivers, floods and the water resources of California. Water, 3, 445-478, https://doi.org/10.3390/w3020445.

Ecklund, W. L., C. R. Williams, P. E. Johnston, and K. S. Gage, 1999: A 3-GHz profiler for precipitating cloud studies. J. Atmos. Oceanic Technol., 16, 309-322, https://doi.org/10.1175/ 1520-0426(1999)016<0309:AGPFPC > 2.0.CO;2.

Fabry, F., A. Bellon, M. R. Duncan, and G. L. Austin, 1994: High resolution rainfall measurements by radar for very small basins: The sampling problem reexamined. J. Hydrol., 161, 415428, https://doi.org/10.1016/0022-1694(94)90138-4

Gershunov, A., T. Shulgina, F. M. Ralph, D. A. Lavers, and J. J. Rutz, 2017: Assessing the climate-scale variability of atmospheric rivers affecting western North America. Geophys. Res. Lett., 44, 7900-7908, https://doi.org/10.1002/2017GL074175.

Gourley, J. J., and B. E. Vieux, 2005: A method for evaluating the accuracy of quantitative precipitation estimates from a hydrologic modeling perspective. J. Hydrometeor., 6, 115-133, https://doi.org/10.1175/JHM408.1.

Habib, E., W. F. Krajewski, and A. Kruger, 2001: Sampling errors of tipping-bucket rain gauge measurements. J. Hydrol. Eng., 6, 159166, https://doi.org/10.1061/(ASCE)1084-0699(2001)6:2(159).

Hecht, C. W., and J. M. Cordeira, 2017: Characterizing the influence of atmospheric river orientation and intensity on precipitation distributions over north coastal California. Geophys. Res. Lett., 44, 9048-9058, https://doi.org/10.1002/2017GL074179.

Henn, B., A. J. Newman, B. Livneh, C. Daly, and J. D. Lundquist 2018: An assessment of differences in gridded precipitation datasets in complex terrain. J. Hydrol., 556, 1205-1219, https:// doi.org/10.1016/j.jhydrol.2017.03.008.

Kim, D., B. Nelson, and D.-J. Seo, 2009: Characteristics of reprocessed Hydrometeorological Automated Data System (HADS) hourly precipitation data. Wea. Forecasting, 24, 1287-1296, https://doi.org/10.1175/2009WAF2222227.1.

Kingsmill, D. E., P. J. Neiman, F. M. Ralph, and A. B. White, 2006: Synoptic and topographic variability of northern California precipitation characteristics in landfalling winter storms during CALJET. Mon. Wea. Rev., 134, 2072-2094, https://doi.org/ 10.1175/MWR3166.1.

Lamjiri, M. A., M. D. Dettinger, F. M. Ralph, and B. Guan, 2017: Hourly storm characteristics along the U.S. West Coast: Role of atmospheric rivers in extreme precipitation. Geophys. Res. Lett., 44, 7020-7028, https://doi.org/10.1002/ 2017GL074193.
Lin, Y., and K. Mitchell, 2005: The NCEP Stage II/IV hourly precipitation analyses: Development and applications. 19th Conf. on Hydrology, San Diego, CA, Amer. Meteor. Soc., 1.2, https://ams.confex.com/ams/Annual2005/techprogram/ paper_83847.htm.

Maddox, R. A., J. Zhang, J. J. Gourley, and K. W. Howard, 2002: Weather radar coverage over the contiguous United States. Wea. Forecasting, 17, 927-934, https://doi.org/10.1175/15200434(2002)017<0927:WRCOTC>2.0.CO;2.

Matrosov, S. Y., F. M. Ralph, P. J. Neiman, and A. B. White, 2014: Quantitative assessment of operational weather radar rainfall estimates over California's Northern Sonoma County using HMT-West data. J. Hydrometeor., 15, 393-410, https://doi.org/ 10.1175/JHM-D-13-045.1.

Mundhenk, B. D., E. A. Barnes, and E. D. Maloney, 2016: Allseason climatology and variability of atmospheric river frequencies over the North Pacific. J. Climate, 29, 4885-4903, https://doi.org/10.1175/JCLI-D-15-0655.1.

Neiman, P. J., F. M. Ralph, A. B. White, D. E. Kingsmill, and P. O. G. Persson, 2002: The statistical relationship between upslope flow and rainfall in California's Coastal Mountains: Observations during CALJET. Mon. Wea. Rev., 130, 1468-1492, https://doi.org/ 10.1175/1520-0493(2002)130<1468:TSRBUF $>2.0 . C O ; 2$

,-- G. A. Wick, J. D. Lundquist, and M. D. Dettinger, 2008: Meteorological characteristics and overland precipitation impacts of atmospheric rivers affecting the west coast of North America based on eight years of SSM/I satellite observations. J. Hydrometeor., 9, 22-47, https://doi.org/10.1175/2007JHM855.1.

Nelson, B. R., O. P. Prat, D.-J. Seo, and E. Habib, 2016: Assessment and implications of NCEP Stage IV quantitative precipitation estimates for product intercomparisons. Wea. Forecasting, 31, 371-394, https://doi.org/10.1175/WAF-D-14-00112.1.

Qi, Y., S. Martinaitis, J. Zhang, and S. Cocks, 2016: A real-time automated quality control of hourly rain gauge data based on multiple sensors in MRMS system. J. Hydrometeor., 17, 16751691, https://doi.org/10.1175/JHM-D-15-0188.1.

Ralph, F. M., P. J. Neiman, G. A. Wick, S. I. Gutman, M. D. Dettinger, D. R. Cayan, and A. B. White, 2006: Flooding on California's Russian River: Role of atmospheric rivers. Geophys. Res. Lett., 33, L13801, https://doi.org/10.1029/ 2006GL026689.

, T. Coleman, P. J. Neiman, R. J. Zamora, and M. D. Dettinger, 2013: Observed impacts of duration and seasonality of atmospheric river landfalls on soil moisture and runoff in coastal northern California. J. Hydrometeor., 14, 443-459, https://doi.org/ 10.1175/JHM-D-12-076.1.

Schaake, J., A. Henkel, and S. Cong, 2004: Application of PRISM climatologies for hydrologic modeling and forecasting in the western U.S. 18th Conf. on Hydrology, Seattle, WA, Amer. Meteor. Soc., 5.3, https://ams.confex.com/ams/84Annual/ techprogram/paper_72159.htm.

Villarini, G., and W. F. Krajewski, 2010: Review of the different sources of uncertainty in single-polarization radar-based estimates of rainfall. Surv. Geophys., 31, 107-129, https://doi.org/ 10.1007/s10712-009-9079-x.

White, A. B., J. R. Jordan, B. E. Martner, F. M. Ralph, and B. W. Bartram, 2000: Extending the dynamic range of an S-band radar for cloud and precipitation studies. J. Atmos. Oceanic Technol., 17, 1226-1234, https://doi.org/10.1175/1520-0426(2000)017<1226: ETDROA $>2.0 . \mathrm{CO} ; 2$

, D. J. Gottas, E. T. Strem, F. M. Ralph, and P. J. Neiman, 2002: An automated brightband height detection algorithm for use with Doppler radar spectral moments. J. Atmos. Oceanic 
Technol., 19, 687-697, https://doi.org/10.1175/1520-0426(2002) 019<0687:AABHDA > 2.0.CO;2.

P. J. Neiman, F. M. Ralph, D. E. Kingsmill, and P. O. G. Persson, 2003: Coastal orographic rainfall processes observed by radar during the California Land-Falling Jets Experiment. J. Hydrometeor., 4, 264-282, https://doi.org/10.1175/1525-7541(2003)4<264: CORPOB $>2.0 . \mathrm{CO} ; 2$.

Wick, G. A., P. J. Neiman, and F. M. Ralph, 2013: Description and validation of an automated objective technique for identification and characterization of the integrated water vapor signature of atmospheric rivers. IEEE Trans. Geosci. Remote Sens., 51, 2166-2176, https://doi.org/10.1109/TGRS.2012.2211024.

Willie, D. H., H. Chen, V. Chandrasekar, R. Cifelli, C. Campbell, D. Reynolds, S. Matrosov, and Y. Zhang, 2017: Evaluation of multisensory quantitative precipitation estimation in Russian
River Basin. J. Hydrol. Eng., 22, E5016002, https://doi.org/ 10.1061/(ASCE)HE.1943-5584.0001422.

Zhang, J., and Coauthors, 2011: National Mosaic and Multi-Sensor QPE (NMQ) system: Description, results, and future plans. Bull. Amer. Meteor. Soc., 92, 1321-1338, https://doi.org/10.1175/ 2011BAMS-D-11-00047.1.

_-, Y. Qi, C. Langston, B. Kaney, and K. Howard, 2014: A realtime algorithm for merging radar QPEs with rain gauge observations and orographic precipitation climatology. J. Hydrometeor., 15, 1794-1809, https://doi.org/10.1175/JHMD-13-0163.1.

_ , and Coauthors, 2016: Multi-Radar Multi-Sensor (MRMS) quantitative precipitation estimation: Initial operating capabilities. Bull. Amer. Meteor. Soc., 97, 621-638, https://doi.org/ 10.1175/BAMS-D-14-00174.1. 